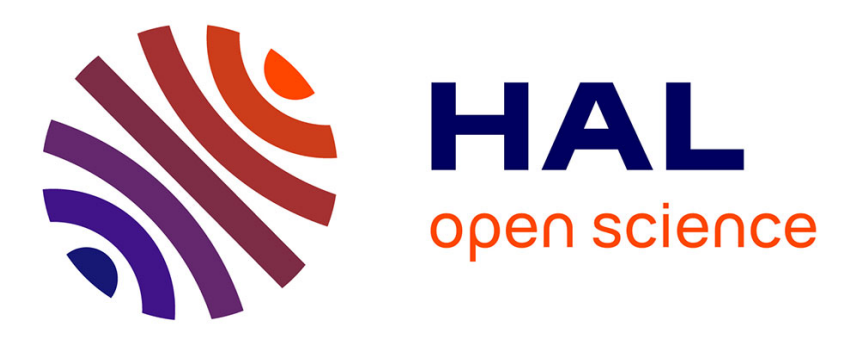

\title{
Cobalt-mediated radical (co)polymerization of vinyl chloride and vinyl acetate
}

Yasmine Piette, Antoine Debuigne, Christine Jérôme, Vincent Bodart, Rinaldo Poli, Christophe Detrembleur

\section{- To cite this version:}

Yasmine Piette, Antoine Debuigne, Christine Jérôme, Vincent Bodart, Rinaldo Poli, et al.. Cobaltmediated radical (co)polymerization of vinyl chloride and vinyl acetate. Polymer Chemistry, 2012, 3 (10), pp.2880-2891. 10.1039/C2PY20413D . hal-03156049

\section{HAL Id: hal-03156049 \\ https://hal.science/hal-03156049}

Submitted on 2 Mar 2021

HAL is a multi-disciplinary open access archive for the deposit and dissemination of scientific research documents, whether they are published or not. The documents may come from teaching and research institutions in France or abroad, or from public or private research centers.
L'archive ouverte pluridisciplinaire $\mathbf{H A L}$, est destinée au dépôt et à la diffusion de documents scientifiques de niveau recherche, publiés ou non, émanant des établissements d'enseignement et de recherche français ou étrangers, des laboratoires publics ou privés. 


\section{Cobalt-Mediated Radical (Co)polymerization of Vinyl Chloride and Vinyl Acetate}

\section{Yasmine Piette ${ }^{1}$, Antoine Debuigne ${ }^{1}$, Christine s Jérôme ${ }^{1}$, Vincent Bodart ${ }^{2}$, Rinaldo Poli ${ }^{3,4}$, Christophe Detrembleur ${ }^{1 *}$}

\section{Received (in $X X X, X X X)$ Xth $X X X X X X X X X 20 X X$, Accepted Xth $X X X X X X X X X 20 X X$ \\ DOI: $10.1039 / b 000000 x$}

10 The Cobalt Mediated Radical Polymerization (CMRP) of vinyl chloride (VC) in the presence of bis(acetylacetonato)cobalt(II) $\left(\mathrm{Co}(\mathrm{acac})_{2}\right)$ as controlling agent is presented for the first time. Using an alkyl-Co(III) compound ( $\mathrm{R}_{0}-\left(\mathrm{CH}_{2}-\mathrm{CHOAc}\right)_{44}$ $\left.\mathrm{Co}(\mathrm{acac})_{2} ; \mathrm{R}_{0}=\left(\mathrm{H}_{3} \mathrm{C}\right)_{2}\left(\mathrm{OCH}_{3}\right) \mathrm{C}-\mathrm{CH}_{2}-\mathrm{C}\left(\mathrm{CH}_{3}\right)(\mathrm{CN})-\right)$ as an 15 initiator, the bulk polymerization under non-isotherm conditions is controlled. ${ }^{1} \mathrm{H}$ NMR spectra of the resulting PVC show that the CMRP process does not significantly affect the level of defects compared to a PVC prepared by a conventional free radical polymerization at the same temperature. Using the same 20 alkyl-cobalt(III) compound, the copolymerization of $\mathrm{VC}$ and VAc is controlled at $40^{\circ} \mathrm{C}$ provided that enough VAc (about 40 $\mathrm{mol} \%$ ) is present in the polymerization medium to moderate the $\mathrm{VC}$ polymerization. In line with reactivity ratios, $\mathrm{VC}$ is preferentially incorporated in the polymer at the early stages of 25 the polymerization, leading to copolymers with a high $\mathrm{VC}$ content at moderate conversions. This is the first report of a CMRP of VC and of the synthesis of well-defined statistical PVC-co-PVAc copolymers by this technique.

\section{Introduction}

${ }_{30}$ Controlling the radical polymerization of vinyl chloride (VC) has long been a challenge because of the high reactivity of the poly(vinyl chloride) (PVC) propagating radical ${ }^{1-3}$. Besides being a non-activated monomer, vinyl chloride is also characterized by one of the largest transfer constants to monomer $\left(\mathrm{C}_{M}=22 \times 10^{-4}\right.$ 35 at $\left.50^{\circ} \mathrm{C}\right)^{4,5}$ among all vinyl monomers (for instance, $\mathrm{C}_{\mathrm{M}}=0.35$ $0.78 \times 10^{-4}, 0.25-4.5 \times 10^{-4}$ and $0.2-0.9 \times 10^{-4}$ for styrene, vinyl acetate and ethyl acrylate, respectively, at $\left.50^{\circ} \mathrm{C}\right),{ }^{4}$ making difficult to control its radical polymerization. Some advances in the development of controlled radical polymerization (CRP) 40 processes have allowed overcoming this problem. Reversible Iodine Transfer Polymerization (RITP), ${ }^{6}$ Nitroxide Mediated Polymerization (NMP) ${ }^{7-8}$ and in-situ $\mathrm{NMP}^{9-10}$ demonstrated some moderate activity for VC. More recently, Percec et al developed the single-electron transfer - degenerative chain transfer living 45 radical polymerization (SET-DTLRP) of vinyl chloride based on activation and deactivation of the propagating chains by copper species issued from disproportionation. ${ }^{3,11-15}$ It provides the best level of control ever achieved for the VC polymerization and gives access to novel PVC based block copolymers. ${ }^{16-21}$ Another 50 copper-assisted system able to mediate the control of VC was developed by the same group, i.e. the Single-Electron Transfer-
Living Radical Polymerization (SET-LRP), where the degenerative transfer pathway was suppressed. ${ }^{22-25}$ Reversible Addition Fragmentation chain Tranfer polymerization (RAFT) 55 also recently emerged as an efficient technique for controlling the radical polymerization of vinyl chloride. ${ }^{26}$

Among the controlled radical polymerization (CRP) techniques presently developed, ${ }^{27-31}$ Cobalt-Mediated Radical Polymerization (CMRP) ${ }^{32-35}$ shows good efficiency for various 60 vinyl monomers. ${ }^{35-40}$ This system, which belongs to the Organometallic Mediated Radical Polymerization (OMRP) class, ${ }^{41-45}$ involves the formation of a reversible carbon-cobalt bond at the polymer chain-end. CMRP involving bis(acetylacetonato)cobalt $\left(\mathrm{Co}(\mathrm{acac})_{2}\right)$ is particularly efficient and ${ }_{65}$ has been proven to be the best CRP technique for vinyl acetate (VAc), a non-conjugated vinyl monomer. Similarities between VAc and VC, i.e. high reactivity of their propagating radicals and propensity to transfer reactions to monomer and polymer, were strong incentives to test $\mathrm{Co}(\mathrm{acac})_{2}$ as controlling agent for the ${ }_{70}$ CMRP of VC.

In this report, first attempts to mediate the VC homopolymerization and copolymerization with vinyl acetate by CMRP are discussed as well as the impact of the cobalt complex on the level of structural defects of PVC. In case of success, the 75 implementation of CMRP to VC would be of high interest for the production of new PVC based copolymers since this technique can be applied to both non-conjugated vinyl monomers (VAc, Nvinyl pyrrolidone, ${ }^{46-48} \mathrm{~N}$-vinyl caprolactame ${ }^{49}$ ) and conjugated ones (acrylonitrile, ${ }^{50-52}$ acrylates ${ }^{53-54}$ ). Moreover, some parameters 80 of the CMRP system can be modulated, such as addition of a neutral ligand, the modulation of the $\beta$-diketonate steric requirements, ${ }^{40,51,55-56}$ or an increase of the polymerization temperature ${ }^{57}$ via the fine-tuning of the C-Co bond strength at the polymer chain-end. The tuning of these parameters opens 85 therefore the door to numerous possibilities to influence the CMRP of VC.

\section{Experimental Part}

\section{Materials}

Vinyl chloride (VC) ( $\geq 99.9 \%$, SolVin SA) was used without 90 prerequisite purification. The polymerizations were carried out in $100 \mathrm{ml}$ stainless steel reactors. VC was condensed under nitrogen pressure to be injected into the reactors. Vinyl acetate (VAc) ( $\geq$ $99 \%$, Aldrich) was dried over calcium hydride, degassed by several freeze-pump-thawing cycles before being distilled under 95 reduced pressure and stored under argon at $-20^{\circ} \mathrm{C}$. Bis(acetylacetonato)cobalt (II) (99\%, Acros), 2,2' -azo-bis-(4methoxy-2,4-dimethyl valeronitrile) $\left(\mathrm{V}-70, \mathrm{t}_{1 / 2}=10\right.$ hours at $30^{\circ} \mathrm{C}$ ) (Wako), 2,2,6,6-tetramethylpiperidine 1-oxy (TEMPO) $(98$ $\%$, Aldrich) were used as received. Dichloromethane $(\geq 99.5 \%$, 100 VWR, Prolabo) and ethyl acetate $(99.8 \%$, Fisher Scientific) were dried over molecular sieves and degassed by bubbling argon for 30 minutes.

\section{Characterizations}

The polymer relative molecular weights (Mn SEC) and mass 105 distribution (Mw/Mn) were determined by size exclusion chromatography (SEC) in a dimethylformamide (DMF)/lithium bromide ( $\mathrm{LiBr}$; $0.025 \mathrm{M}$ ) solution (flow rate: $1 \mathrm{~mL} \mathrm{~min}^{-1}$ ) at $55^{\circ} \mathrm{C}$ 
using a Waters 600 liquid chromatograph equipped with a 2414 refractive index detector (RI) and four Styragel HR columns (HR1 (100-500), HR3 (500-30000), HR4 (5000-50000), HR5 (2000-4000000)). Calibration with poly(methyl methacrylate) 5 standards was used to determine the relative molecular weights of poly(vinyl chloride). The absolute molecular weights for the PVC samples were also determined by SEC in DMF- $\mathrm{LiBr}$ equipped with a Wyatt multi-angle laser light scattering (MALLS) detector (120mW solid-state laser, $\lambda=658 \mathrm{~nm}$, Dawn Heleos S/N 342-H). ${ }_{10}$ Data were processed with the Astra V software (Wyatt Technology). ${ }^{1} \mathrm{H}$ NMR spectra were recorded with a Bruker AM 400 Spectrometer $(400 \mathrm{MHz})$ in deuterated tetrahydrofuran as a solvent. The cobalt concentration of the alkyl-Co(III) compound stock solution in dichloromethane was determined by Inductively 15 Coupled Plasma-Mass Spectroscopy (ICP-MS). Atomic Emission Spectroscopy was carried out with a spectrometer (Elan DRC-e Perkin-Elmer SCIEX). Samples were prepared by dissolving $1 \mathrm{ml}$ of the alkyl-Co(III) compound solution (in dichloromethane, previously evaporated under vacuum) in $1 \mathrm{ml}$ of $\mathrm{HNO}_{3}(65 \%)$ at ${ }_{20} 60^{\circ} \mathrm{C}$ for 2 hours. These solutions were diluted with $250 \mathrm{ml}$ of bidistilled water at room temperature prior to ICP-MS analysis. DSC curves were recorded with a TA DSC Q 100 thermal analyzer calibrated with indium.

\section{Procedures for polymerizing VC.}

${ }_{25}$ PVC syntheses were carried out in $100 \mathrm{ml}$ and 3 liter stainless steel reactors. In both facilities, VC was injected under nitrogen pressure into the reactors via stainless steel pipes. The amount of $\mathrm{VC}$ injected into the reactor was regulated by weighing the $\mathrm{VC}$ cylinder during the VC addition. A vertical agitating axe 30 performed the agitation, which was regulated at about $200 \mathrm{rpm}$.

At the end of the polymerization, the reaction medium was cooled down to room temperature and the residual VC was degassed. When the degassing was over, the polymerization underwent a thermal treatment called "stripping", which 35 consisted in blowing nitrogen into the polymerization medium in order to remove VC that was not evacuated during degassing. At the end of this thermal treatment, the reactor was opened and the PVC product was recovered.

It is important to note that at the end of each polymerization, after 40 the $\mathrm{VC}$ degassing and prior to the stripping, an excess of 2,2,6,6tetramethyl-1-piperidinyloxy (TEMPO) (in solution in THF) was added to the reactor in order to irreversibly terminate the polymerization. The nitroxyl radicals irreversibly end-cap the polymer chains, releasing the cobalt complex. ${ }^{38}$ Therefore, when

45 the stripping is carried out at the polymerization temperature, the polymer chains should not undergo further polymerization or side reactions.

General procedure for the alkyl-cobalt(III) compound synthesis and purification

50 According to the literature, ${ }^{54} 34 \mathrm{~g}$ of $\mathrm{Co}(\mathrm{acac})_{2}\left(1.32 \times 10^{-1} \mathrm{~mol}\right)$ and $20 \mathrm{~g}$ of $\mathrm{V}-70\left(6.5 \times 10^{-2} \mathrm{~mol}\right)$ were added in a $1 \mathrm{~L}$ roundbottomed flask capped by a three-way stopcock and degassed by three vacuum-argon cycles. $100 \mathrm{ml}$ of vinyl acetate $(1.08 \mathrm{~mol})$ were then added and the mixture was stirred and heated at $30^{\circ} \mathrm{C}$ 55 for about 70 hours. The medium remained pink throughout the reaction, with no increase in viscosity. The unreacted vinyl acetate was evaporated under reduced pressure at room temperature. The residual mixture was placed under argon and then diluted into dry and degassed dichloromethane, ready for 60 purification by chromatographic separation under an inert atmosphere. The solution was transferred by cannula to a silicagel column placed under argon and equipped with a three-way stopcock at the bottom and with dry and degassed $\mathrm{CH}_{2} \mathrm{Cl}_{2}$ as eluent. After the elimination of the V-70 residues (yellow 65 colored) with $\mathrm{CH}_{2} \mathrm{Cl}_{2}$, a green fraction was collected with $\mathrm{CH}_{2} \mathrm{Cl}_{2}$ /EtOAc $(75: 25)$ as eluent. Finally, the pink fraction corresponding to the alkyl-Co(III) compound $\left(\mathrm{R}_{0}-\mathrm{CH}_{2}-\right.$ $\mathrm{CHOAc}_{4}-\mathrm{Co}(\mathrm{acac})_{2} ; \quad \mathrm{R}_{0}=$ primary radical from the $\mathrm{V}-70$ decomposition) was collected with EtOAc as eluent and was 70 dried under vacuum. The alkyl-Co(III) compound was obtained as a pink sticky solid and was conserved under argon at $-20^{\circ} \mathrm{C}$ after dilution with $40 \mathrm{ml}$ of degassed dichloromethane. The cobalt concentration was measured by ICP $\left([\mathrm{Co}]=1.56 \times 10^{-1} \mathrm{~mol} / \mathrm{L}\right)$.

Typical procedure for the vinyl chloride bulk polymerization ${ }_{75}$ mediated by the alkyl-Co(III) compound

The alkyl-Co(III) solution in dichloromethane $\left(2 \mathrm{ml}, \mathrm{Co}(\mathrm{acac})_{2}=\right.$ $3.13 \times 10^{-4} \mathrm{~mol}$ ) were added to a $100 \mathrm{ml}$ stainless steel reactor under a nitrogen flux. The reactor was closed and the dichloromethane evaporated under vacuum for 15 minutes. The 80 reactor was degassed by five vacuum-nitrogen cycles. $60 \mathrm{~g}$ of $\mathrm{VC}$ $(0.96 \mathrm{~mol})$ were then injected in the reactor under nitrogen pressure. The mixture was stirred and heated at the desired temperature, and at the end of the polymerization, the reactor was degassed to eliminate the unreacted vinyl chloride. Then a 85 TEMPO solution in THF $\left(20 \mathrm{ml}\right.$, [TEMPO] $\left.=4.7 \times 10^{-2} \mathrm{~mol} / \mathrm{L}\right)$ was added to kill the reaction before stripping at $40^{\circ} \mathrm{C}$ for $2 \mathrm{~h}$. The reactor was opened and the homopolymer was recovered. For the polymerizations carried out in the presence of a ligand, the latter was injected before degassing by five vacuum-nitrogen 90 cycles.

\section{General procedure for the bulk vinyl chloride/vinyl acetate} statistical copolymerization initiated by V-70

V-70 (0.0856 g, $\left.2.78 \times 10^{-4} \mathrm{~mol}\right)$ was added in the reactor, and then $24 \mathrm{ml}$ of vinyl acetate $\left(2.6 \times 10^{-1} \mathrm{~mol}\right)$ were added under a 95 nitrogen flux. The reactor was degassed by five vacuum-nitrogen cycles and $8 \mathrm{~g}$ of vinyl chloride $\left(1.3 \times 10^{-1} \mathrm{~mol}\right)$ were then injected under nitrogen pressure. The mixture was stirred and heated to $40^{\circ} \mathrm{C}$ for $1.5 \mathrm{~h}$. At the end of the polymerization, the reactor was degassed to eliminate the unreacted vinyl chloride. 100 Then, a TEMPO solution in THF (20 ml, $\left.4.17 \times 10^{-2} \mathrm{~mol} / \mathrm{L}\right)$ was added before stripping at $40^{\circ} \mathrm{C}$ for two hours. The reactor was opened and the copolymer PVC-co-PVAc (table 5, entry 4) was recovered.: Mn (MALLS) $=47500 \mathrm{~g} / \mathrm{mol} ; \mathrm{VC}$ conversion $=19$ $\%$; VAc conversion $=6 \%$; VC composition in the copolymer $=$ $10560 \%$; VAc composition in the copolymer $=40 \%$.

General procedure for the bulk vinyl chloride/vinyl acetate statistical copolymerization in the presence of V-70 and $\mathrm{Co}(\mathrm{acac})_{2}$

V-70 $\left(0.0856 \mathrm{~g}, 2.78 \times 10^{-4} \mathrm{~mol}\right)$ and $0.0715 \mathrm{~g}$ of $\mathrm{Co}(\mathrm{acac}) 2(2.78$ $\left.110 \times 10^{-4} \mathrm{~mol}\right)$ were added in the reactor, and then $24 \mathrm{ml}$ of vinyl acetate $\left(2.6 \times 10^{-1} \mathrm{~mol}\right)$ were added under a nitrogen flux. The reactor was degassed by five vacuum-nitrogen cycles and $8 \mathrm{~g}$ of vinyl chloride $\left(1.3 \times 10^{-1} \mathrm{~mol}\right)$ were then injected under nitrogen 
pressure. The mixture was stirred and heated to $40^{\circ} \mathrm{C}$. At the end of the polymerization, the reactor was degassed to eliminate the unreacted vinyl chloride. A TEMPO solution in THF $(20 \mathrm{ml}, 4.17$ $\mathrm{x} 10^{-2} \mathrm{~mol} / \mathrm{L}$ ) was added prior to stripping at $40^{\circ} \mathrm{C}$ for $2 \mathrm{~h}$. The 5 reactor was opened and no copolymer was recovered (table 5, entries 7 and 8).

Conversions of VC and VAc during the statistical copolymerization were determined on the basis of the $\mathrm{VC}$ composition (measured by ${ }^{1} \mathrm{H}$ NMR), the initial VC and VAc 10 masses, the VC and VAc molecular weights, and the final total mass of the obtained copolymer. Conversions were therefore determined by the resolution of a system of two equations with two unknowns, i.e. :

(1) $\mathrm{VC}$ composition $=\left(\left(\mathrm{mvc}_{\mathrm{vC}} / \mathrm{MMVC}_{\mathrm{vC}}\right) \mathrm{xC}\right.$ conv $) /\left(\left(\left(\mathrm{m}_{\mathrm{VC}} / \mathrm{MMVC}_{\mathrm{VC}}\right)\right.\right.$ $15 \mathrm{x}$ VC conv $)+\left(\left(\right.\right.$ mvAc$\left._{\mathrm{V}} / \mathrm{MMVAc}_{\mathrm{VA}}\right) \mathrm{x} \mathrm{VAc}$ conv $\left.)\right)$

(2) $\mathrm{m}_{\text {copolymer }}=\left(\mathrm{mvc}_{\mathrm{x}} \mathrm{VC}\right.$ conv $)+(\operatorname{mvAc} \mathrm{x} \mathrm{VAc}$ conv $)$

where $\mathrm{VC}$ composition = the $\mathrm{VC}$ composition in the copolymer; $\mathrm{mvC}_{\mathrm{V}}=$ the initial $\mathrm{VC}$ mass, $\mathrm{MMvC}=\mathrm{VC}$ molecular weight, mvAc $=$ the initial $\mathrm{VAc}$ mass, $\mathrm{MM}_{\mathrm{VAc}}=\mathrm{VAc}$ molecular weight,

$20 \mathrm{~m}_{\text {copolymer }}=$ the final total mass of the obtained copolymer.

The theoretical VC composition in the copolymer shown in figures 4 and 6 were calculated on the basis of the integration of the differential Alfrey, Mayo and Lewis' equation: ${ }^{58}$

$\mathbf{F}_{\mathrm{VC}}=\left(\left(\mathrm{rVC}_{\mathrm{VC}} \mathrm{f}_{\mathrm{VC}}{ }^{2}\right)+\left(\mathrm{f}_{\mathrm{VC}} \mathrm{x} \mathrm{fVAc}_{\mathrm{VAC}}\right)\right) /\left(\left(\mathrm{rVC}_{\mathrm{VC}} \mathrm{fVC}^{2}\right)+\left(2 \mathrm{f}_{\mathrm{VC}} \mathrm{x} \mathrm{f}_{\mathrm{VAc}}\right)+\right.$ $\left.25\left(\operatorname{rVAc} X \mathrm{fVAc}^{2}\right)\right)$

where $\mathrm{FvC}_{\mathrm{VC}}=$ the mole fraction of vinyl chloride in the copolymer formed at a particular instant in time, $r=$ the monomer reactivity ratio, $f=$ the mole fraction of a monomer in the comonomer mixture.

${ }_{30}$ General procedure for the bulk vinyl chloride/vinyl acetate statistical copolymerization initiated by the alkylcobalt(III) compound

The alkyl-Co(III) solution in dichloromethane $\left(2 \mathrm{ml}, 2.78 \times 10^{-4}\right.$ mol of alkyl-Co(III)) was added to a $100 \mathrm{ml}$ stainless reactor 35 under a nitrogen flux. The reactor was closed and the dichloromethane evaporated under vacuum for 15 minutes. Vinyl acetate $\left(24 \mathrm{ml}, 2.6 \times 10^{-1} \mathrm{~mol}\right)$ was then added under a nitrogen flux and the reactor was closed before degassing by five vacuumnitrogen cycles. Vinyl chloride $\left(8 \mathrm{~g}, 1.3 \times 10^{-1} \mathrm{~mol}\right)$ was injected 40 in the reactor under nitrogen pressure. The mixture was then stirred and heated to $40^{\circ} \mathrm{C}$. After $6 \mathrm{~h}$ of polymerization, the reactor was degassed to eliminate the unreacted vinyl chloride. A
TEMPO solution in THF (20 ml, $\left.4.17 \times 10^{-2} \mathrm{~mol} / \mathrm{L}\right)$ was added prior to stripping at $40^{\circ} \mathrm{C}$ for $2 \mathrm{~h}$. The reactor was opened and the ${ }_{45}$ copolymer was recovered. The statistical copolymer PVC-coPVAc was characterized by ${ }^{1} \mathrm{H}$ NMR (figure 11) and by SEC MALLS (table 5, entry 3): Mn,MALLS = $56000 \mathrm{~g} / \mathrm{mol} ; \mathrm{VC}$ conversion $=79 \%$, VAc conversion $=44 \%$, VC composition in the copolymer $=50 \%$; VAc composition in the copolymer $=50$ ${ }_{50} \%$.

\section{Results and Discussion}

Bulk VC polymerization initiated by $\mathrm{V}-70$ in the presence of $\mathrm{Co}(\mathrm{acac})_{2}$.

When using a $\mathrm{Co}(\mathrm{acac})_{2} / \mathrm{V}-70$ molar ratio of $1 / 1$ at $40^{\circ} \mathrm{C}$, the 55 monomer conversion evolved from 3 to $6 \mathrm{~h}$ of polymerization, with only a slight increase of molar masses (Table 1). However, there was no further conversion when the polymerization time was extended to $8 \mathrm{~h}$. This indicates that the polymerization occurs within the first 6 hours and stops at about $19 \%$ of VC 60 conversion. The overlay of SEC chromatograms clearly evidences that the molecular weight does not increase significantly with the monomer conversion (Figure 1), in contrast to what is expected for a controlled process. Interestingly, when we compare this experiment with the reference experiment ${ }_{65}$ carried out under the same conditions but in the absence of $\mathrm{Co}(\mathrm{acac})_{2}$ (Table 1, entry REF), it clearly appears that adding $\mathrm{Co}(\mathrm{acac})_{2}$ to the $\mathrm{VC}$ polymerization negatively affects the monomer conversion and the molar masses of the resulting polymer. No control of the VC radical polymerization was 70 observed under these conditions, in sharp contrast with the CMRP of VAc that gave access to poly(vinyl acetate) (PVAc) with well-defined molecular parameters (Figure 2a). Under the same experimental conditions, an induction period of about $16 \mathrm{~h}$ was observed for the VAc polymerization while some polymer 75 (about 8\% monomer conversion; Table 1, entry 1) was already collected after $3 \mathrm{~h}$ of $\mathrm{VC}$ polymerization. The induction period for the VC polymerization is therefore much shorter than for the VAc polymerization. This suggests that $\mathrm{Co}(\mathrm{acac})_{2}$ traps the PVC radicals less efficiently than the PVAc radicals, suggesting that 80 the C-Co bond at the polymer chain-end is weaker in PVC than in PVAc.

Table 1. Conditions and results for the VC polymerization initiated by $\mathrm{V} 70$ in the presence of $\mathrm{Co}(\mathrm{acac})_{2}$ in bulk at $40^{\circ} \mathrm{C}$

\begin{tabular}{cccccccc}
\hline Entry & Polym time & $\begin{array}{c}\text { VC } \\
\text { conversion } \\
\text { (a) }\end{array}$ & $\begin{array}{c}\text { Mn th } \\
(\mathbf{g} / \mathbf{m o l}) \\
\text { (b) }\end{array}$ & $\begin{array}{c}\text { Mn SEC DMF-LiBr } \\
(\mathbf{g} / \mathbf{m o l})\end{array}$ & $\begin{array}{c}\text { Mw/Mn } \\
\text { SEC } \\
\text { (c) }\end{array}$ & $\begin{array}{c}\text { Mn MALLS } \\
\text { (g/mol) }\end{array}$ & $\begin{array}{c}\text { f } \\
(\mathrm{e})\end{array}$ \\
\hline $\begin{array}{c}\text { REF } \\
\text { (f) }\end{array}$ & $6 \mathrm{~h} 00$ & $59 \%$ & $/$ & 68200 & 2.13 & 56000 & $/$ \\
\hline $\mathbf{1}$ & $3 \mathrm{~h} 00$ & $8 \%$ & 3200 & 16500 & 2.32 & 16900 & 0.19 \\
$\mathbf{2}$ & $6 \mathrm{~h} 00$ & $19 \%$ & 7600 & 21600 & 2.48 & 23400 & 0.32 \\
$\mathbf{3}$ & $8 \mathrm{~h} 00$ & $18 \%$ & 7200 & 20100 & 2.24 & 20500 & 0.35 \\
\hline
\end{tabular}

Conditions: $\mathrm{VC}(500 \mathrm{~g}, 8 \mathrm{~mol})$ polymerization in bulk at $40^{\circ} \mathrm{C}$ initiated by V-70 $\left(4 \mathrm{~g}, 1.29 \times 10^{-2} \mathrm{~mol}\right)$ in the presence of $\mathrm{Co}(\mathrm{acac})_{2}\left(3.2 \mathrm{~g}, 1.25 \mathrm{x} 10^{-2}\right.$ $85 \mathrm{~mol}) ;\left[\mathrm{Co}(\mathrm{acac})_{2}\right] /[\mathrm{V} 70] /[\mathrm{VC}]=1 / 1 / 643$. 
(a) VC conversion calculated gravimetrically; (b) theoretical Mn calculated on the basis of VC conversion and the cobalt concentration using the following equation: $\mathrm{Mn}$ th $=$ (conversion) $\mathrm{x}\left(\mathrm{m}(\mathrm{VC}) / \mathrm{n}\left(\mathrm{Co}(\mathrm{acac})_{2}\right)\right.$; (c) SEC DMF- $\mathrm{LiBr}$, calibrated by PMMA; (d) Mn SEC with MALLS detection; (e) initiation efficiency factor $\mathrm{f}=\mathrm{Mn}$ th/ $\mathrm{Mn} \exp$; (f) VC free-radical polymerization in bulk at $40^{\circ} \mathrm{C}$ initiated by V-70; [VC]/[V-70] $=643 / 1$.

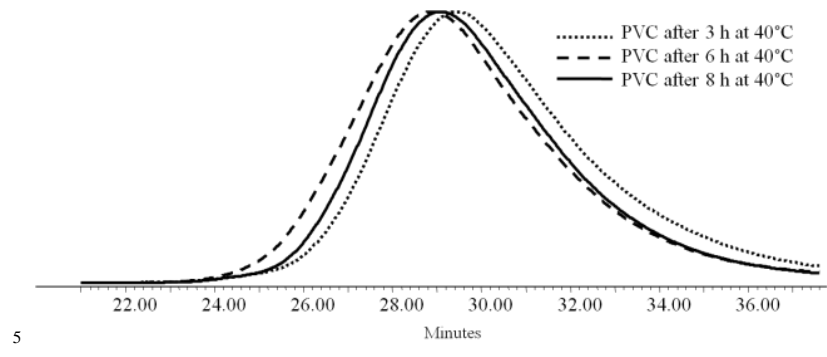

Figure 1. PVC chromatograms obtained for the VC polymerization initiated by $\mathrm{V}-70$ in the presence of $\mathrm{Co}(\mathrm{acac})_{2}$ in bulk at $40^{\circ} \mathrm{C}$ $\left(\left[\mathrm{Co}(\mathrm{acac})_{2}\right] /[\mathrm{V} 70] /[\mathrm{VC}]=1 / 1 / 643\right)$.
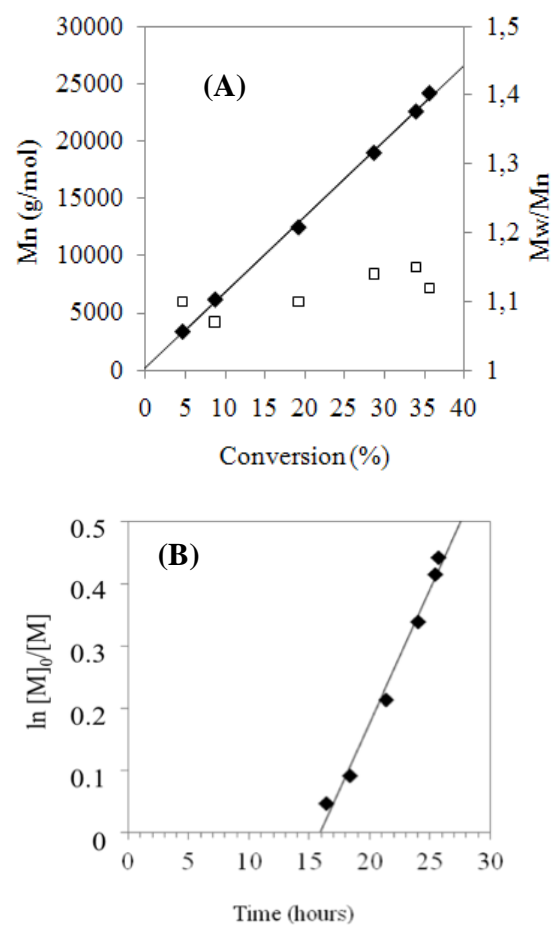

10 Figure 2. Vinyl acetate CMRP initiated by V-70 in the presence of $\mathrm{Co}(\mathrm{acac})_{2}$. Conditions: bulk, $40^{\circ} \mathrm{C}$ with $\left[\mathrm{Co}(\text { acac })_{2}\right] /[\mathrm{V} 70] /[\mathrm{VAc}]=$ 1/1/643. (a) ( ) Molar mass versus VAc conversion and $(\square)$ Mass distribution versus conversion; (b) Time dependence of $\ln \left([\mathrm{M}]_{0} /[\mathrm{M}]\right)$.
VC homopolymerization initiated by alkyl-cobalt(III) in bulk at $40^{\circ} \mathrm{C}$. A preformed alkyl-Co(III) adduct $\left(\mathrm{R}_{0}-\left(\mathrm{CH}_{2}-\right.\right.$ $\mathrm{CHOAc}_{<4}-\mathrm{Co}(\mathrm{acac})_{2} ; \mathrm{R}_{0}=$ primary radical from the $\mathrm{V}-70$ decomposition $=\left(\mathrm{H}_{3} \mathrm{C}\right)_{2}\left(\mathrm{OCH}_{3}\right) \mathrm{C}-\mathrm{CH}_{2}-\mathrm{C}\left(\mathrm{CH}_{3}\right)(\mathrm{CN})-$; ${ }_{20}$ Scheme 1$)^{55}$ that mimics a PVAc-Co(acac)2 dormant chain demonstrated the best efficiency to initiate and control the polymerization of VAc upon dissociation. Indeed, it was shown that this alkyl-cobalt(III) adduct suppressed the induction period while improving the control on the VAc radical 25 polymerization. More importantly, by suppressing this induction period, it also improved the level of control over the polymerization of conjugated monomers such as acrylonitrile ${ }^{50-}$ 52 and $n$-butyl acrylate ${ }^{53}$ compared to the polymerizations carried out with the V-70/Co(acac) 2 binary system.

30

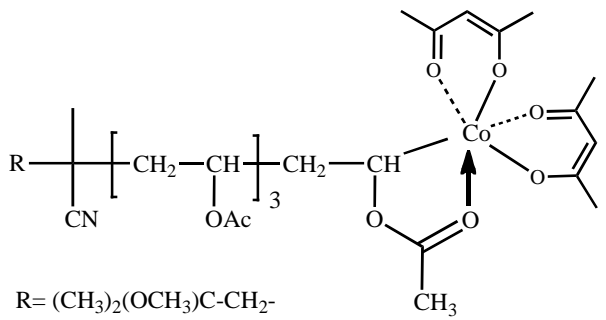

Scheme 1: Structure of the alkyl-Co(III) compound $\left(\mathrm{R}_{0}-\left(\mathrm{CH}_{2}-\right.\right.$ $\mathrm{CHOAc}_{4}-\mathrm{Co}(\mathrm{acac})_{2} ; \mathrm{R}_{0}=$ primary radical from the $\mathrm{V}-70$ 35 decomposition) used for the CMRP of vinyl acetate, acrylonitrile and n-butyl acrylate.

Because this alkyl-Co(III) adduct proved efficiency for monomers that form a weak C-Co bond at the polymer chain end, it was therefore tested for the polymerization of $\mathrm{VC}$. 40 Different VC/alkyl-cobalt(III) molar ratios were investigated in order to emphasize the possibility for the cobalt to affect the poly(vinyl chloride) (PVC) molar mass. When the vinyl chloride homopolymerization was initiated at $40^{\circ} \mathrm{C}$ by the alkyl-Co(III) compound, the VC conversion was very low after $451.5 \mathrm{~h}$ of polymerization and did not further evolve (i.e. after 3 and $6 \mathrm{~h}$ ) for all VC/alkyl-cobalt(III) molar ratios investigated (Table 2). These observations suggest that the polymerization stops rapidly after the initiation, as observed with the V$70 / \mathrm{Co}(\mathrm{acac}) 2$ system. 
Table 2. Bulk VC polymerizations initiated by $\mathrm{R}_{0}-\left(\mathrm{CH}_{2}-\mathrm{CHOAc}\right)_{4}-\mathrm{Co}(\mathrm{acac})_{2}$ at $40^{\circ} \mathrm{C}$.

\begin{tabular}{|c|c|c|c|c|c|c|c|c|}
\hline Entry & $\begin{array}{c}\text { Polym. } \\
\text { time }\end{array}$ & $\begin{array}{c}\text { [VC]/ } \\
\text { [alkyl- } \\
\text { Co(III)] }\end{array}$ & $\begin{array}{c}\mathrm{VC} \\
\text { conv } \\
(a)\end{array}$ & $\begin{array}{c}\text { Mn th } \\
(\mathrm{g} / \mathrm{mol})^{(\mathrm{b})}\end{array}$ & $\begin{array}{c}\text { Mn SEC } \\
\text { DMF-LiBr } \\
(\mathrm{g} / \mathrm{mol})^{(\mathrm{c})}\end{array}$ & $\begin{array}{c}\text { Mw/Mn } \\
\text { SEC DMF- } \\
\text { LiBr }^{(c)}\end{array}$ & $\begin{array}{c}\text { Mn } \\
\text { MALLS } \\
(\mathrm{g} / \mathrm{mol})^{(d)} \\
\end{array}$ & $\begin{array}{c}\mathbf{f} \\
(\mathrm{e})\end{array}$ \\
\hline $\mathbf{R E F}^{(\mathbf{f})}$ & $6 \mathrm{~h} 00$ & 1 & $59 \%$ & I & 68200 & 2.13 & 56000 & I \\
\hline 1 & $1 \mathrm{~h} 30$ & $6500: 1$ & $4 \%$ & 16300 & 32400 & 2.56 & 34600 & 0.47 \\
\hline 2 & $3 \mathrm{~h} 00$ & 6500:1 & $3 \%$ & 12200 & 22500 & 2.50 & 23500 & 0.52 \\
\hline 3 & $6 \mathrm{~h} 00$ & 6500:1 & $4 \%$ & 16300 & 22800 & 2.59 & 23800 & 0.68 \\
\hline 4 & $1 \mathrm{~h} 30$ & $3250: 1$ & $5 \%$ & 10200 & 18500 & 1.90 & 17300 & 0.59 \\
\hline 5 & $3 \mathrm{~h} 00$ & 3250:1 & $4 \%$ & 8100 & 15000 & 1.98 & 15600 & 0.52 \\
\hline 6 & $6 \mathrm{~h} 00$ & 3250:1 & $6 \%$ & 12200 & 20400 & 2.48 & 19400 & 0.63 \\
\hline 7 & $1 \mathrm{~h} 30$ & $1625: 1$ & $8 \%$ & 8100 & 15000 & 1.80 & 13500 & 0.60 \\
\hline 8 & $3 \mathrm{~h} 00$ & $1625: 1$ & $7 \%$ & 7100 & 13500 & 1.93 & 13500 & 0.53 \\
\hline 9 & $6 \mathrm{~h} 00$ & $1625: 1$ & $7 \%$ & 7100 & 13400 & 1.92 & 13100 & 0.54 \\
\hline
\end{tabular}

(a) Calculated gravimetrically after precipitation of the sample in cold heptane ; (b) Calculated on the basis of VC conversion and the cobalt concentration using the following equation: Mn th = (conversion) $\mathrm{x}(\mathrm{m}(\mathrm{VC}) / \mathrm{n}($ alkyl-Co (III)); (c) obtained by SEC, in DMF-LiBr, with a PMMA calibration; (d) SEC analysis with MALLS detection, in DMF-LiBr where $\mathrm{dn} / \mathrm{dc}=0.0793$; (e) initiator efficiency factor $\mathrm{f}=\mathrm{Mn}$ th $/ \mathrm{Mn}$ exp; (f) VC free-radical polymerization 5 in bulk at $40^{\circ} \mathrm{C}$ initiated by V-70; [VC]/[V-70] $=643 / 1$.

In line with these observations, the SEC chromatograms of PVC are identical after $1.5,3$ and 6 h of polymerization (Figure 10 3). It also appears that slightly higher VC conversions are obtained when the VC/initiator molar ratio is decreased, e.g. they increase from about 3-4\% when $[\mathrm{VC}] /[$ alkyl-Co(III)] = 6500 to about $7-8 \%$ when $[\mathrm{VC}] /[$ alkyl-Co(III)] $=1625$. Importantly, although the monomer conversion is very low, the ${ }_{15}$ PVC molecular weight seems to depend on the monomer/initiator molar ratio, as would be expected for a controlled process. The initiator efficiency ( $\left.\mathrm{f}=\mathrm{Mn}_{\mathrm{th}} / \mathrm{Mn}_{\text {MALLS }}\right)$ is in the same range for all VC/alkyl-Co(III) molar ratios, i.e. around $0.47-0.68$, meaning that only $47 \%$ to $68 \%$ of the alkyl20 cobalt(III) initiator contributes to the initiation of PVC chains.

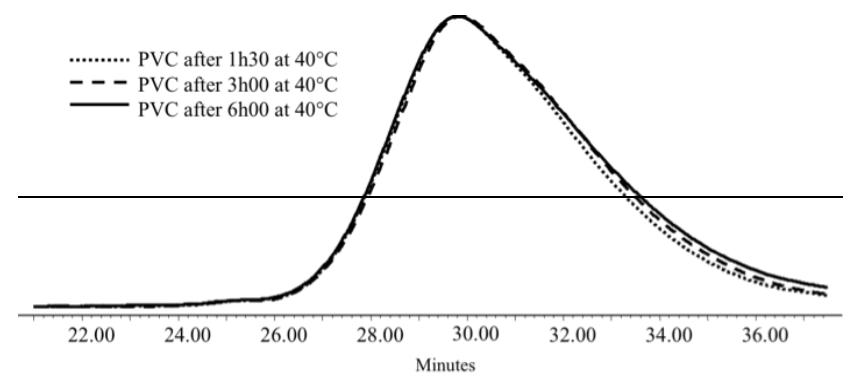

Figure 3. SEC chromatograms obtained for the bulk VC polymerization initiated by alkyl-cobalt(III) at $40^{\circ} \mathrm{C}$. Conditions: 25 $[\mathrm{VC}] /[$ initiator $]=1625 / 1 ;$ Table 2 , entries 7-9.
Note that in free radical polymerization, the PVC molecular weight depends only on the polymerization temperature..$^{59-60}$

30 However, at the same temperature, i.e. $40^{\circ} \mathrm{C}$, the molar mass of PVC produced in the presence of cobalt is lower than that obtained without $\mathrm{Co}(\mathrm{acac})_{2}$ (REF, table 2), indicating that the cobalt complex has an influence on the VC polymerization. Moreover, the fact that all $\mathrm{VC}$ polymerizations stop at low 35 conversion raises questions. Several hypotheses can be made to explain such observations.

The first hypothesis invokes the occurrence of irreversible $\mathrm{H}$ atom transfer reactions. Indeed, it is known that some cobalt(II) 40 complexes, e.g. cobaloximes and cobalt porphyrins, are effective chain transfer catalysts responsible for the moderation of the molar mass of polymers prepared by radical polymerization, ${ }^{61-63}$ particularly poly(alkyl methacrylate)s. According to the commonly accepted mechanism, a cobalt(II) 45 complex can undergo hydrogen atom abstraction with release of a polymer chain with an unsaturated end-group and formation of a cobalt hydride. The catalytic cycle is closed by generation of a primary radical by hydrogen transfer from the cobalt hydride complex to the methacrylate monomer unit, ${ }_{50}$ followed by propagation. A similar behavior might therefore be expected for the VC polymerization initiated by the alkyl$\mathrm{Co}$ (III) provided that the cobalt complex at the PVC chain-end is prone to dehydrocobaltation. The VC polymerization might stop at low conversion if the generated cobalt hydride complex 
is not able to transfer to $\mathrm{VC}$ monomer to reinitiate the polymerization. The formation of this cobalt hydride will therefore result in a termination reaction and is also in line with a decrease of the PVC molecular weight when higher amounts 5 of alkyl-Co(III) are used. The possibility of $\mathrm{Co}(\mathrm{acac})_{2}$ to favor this $\beta-\mathrm{H}$ elimination was investigated by calculating the energetics of the $\beta-\mathrm{H}$ elimination process from the PVC$\mathrm{Co}(\mathrm{acac})_{2}$ dormant chain (corresponding to the process indicated in Figure 3). This was accomplished computationally 10 by modeling the polymer chain ( $\mathrm{P}$ in Figure 4 ) by an $\mathrm{H}$ atom. Although modelling the polymer chain beyond the metalbonded monomer unit by a simple $\mathrm{H}$ atom may not be the most appropriate choice, this replacement greatly simplifies the computational task and is not expected to introduce a great 15 systematic error. Indeed, the effect on the Co-C bond strength should be negligible since the residue is located on the $\beta-C$ atom and does not transmit any mesomeric effects to the generated radical. On the other hand, the residue could have an effect on the stabilization of the olefin product, but this should 20 be small and identical for the two types of $\beta-\mathrm{H}$ elimination processes (from the HH and HT chain ends).

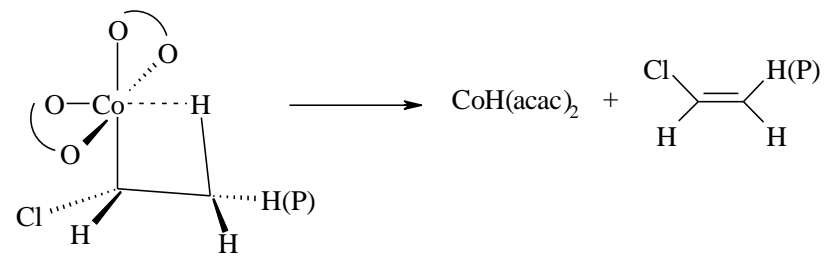

Figure 3. $\beta$-H elimination from $\mathrm{PVC}-\mathrm{Co}(\mathrm{acac})_{2}$ dormant chain (head-to-tail addition).

It can be seen from Figure 4 that this dehydrocobaltation is rather difficult from the PVC dormant chain. A costly geometric reorganization of the cobalt complex $(\sim 13 \mathrm{kcal} / \mathrm{mol}$, ${ }_{30}$ Figure 4, blue pathway) has first to occur in order to allow the $\beta-\mathrm{H}$ elimination process to take place from the higher-energy equatorial isomer, because the $\beta-\mathrm{H}$ elimination mechanism requires a vacant coordination site cis to the alkyl ligand. The next intermediate is a 5-coordinate hydride complex at very 35 high energy, with the hydride in the unfavorable equatorial position. Even if this high-energy intermediate may be avoided, depending on the mechanistic details of the $\beta-\mathrm{H}$ elimination process (detailed calculation of transition states were not carried out), the total energy cost for dehydrocobaltation is 40 around $22 \mathrm{kcal} / \mathrm{mol}$, which makes the process difficult. Furthermore, the reverse process is thermodynamically favorable, therefore the $\mathrm{H}$-atom transfer, if occurring at all, would be predicted to serve as a chain transfer process and not as a termination event.

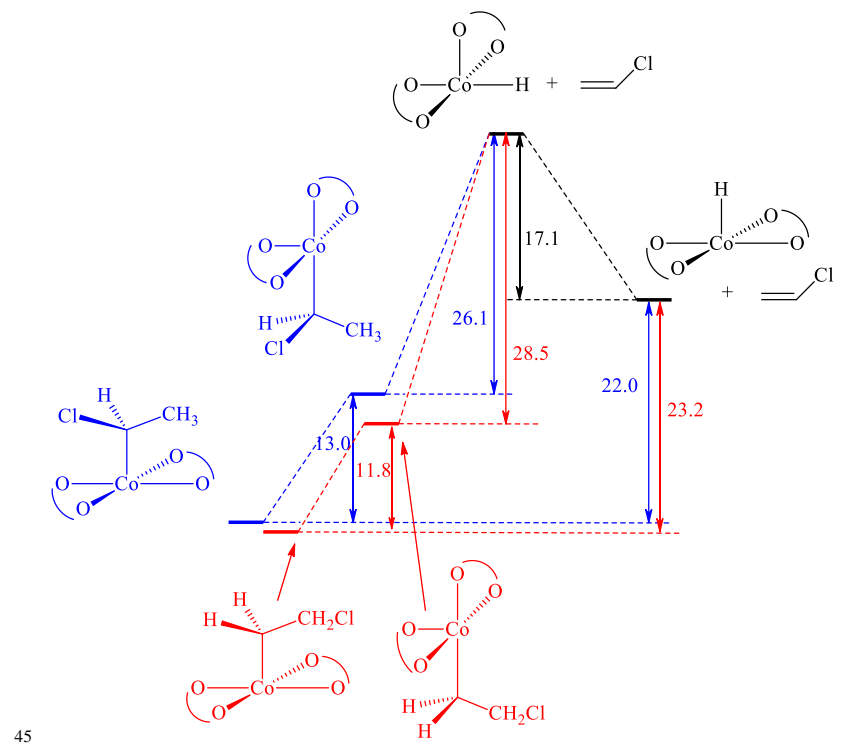

Figure 4. Energetics (in $\mathrm{kcal} / \mathrm{mol}$ ) of the $\beta$ - $\mathrm{H}$ elimination process from a model PVC-Co(acac) 2 dormant chain.

Because VC polymerization is also prone to head-to-head addition, the propensity to dehydrocobaltation of the 50 corresponding PVC-Co(acac)2 dormant chain (formed by headto-head addition mode, even if followed by the well-known rearrangement of $\mathrm{P}-\mathrm{CHCl}-\mathrm{CH}_{2}{ }^{\circ}$ radical in the more stable $\mathrm{P}$ $\mathrm{CH}^{\circ}-\mathrm{CH}_{2}-\mathrm{Cl}$, Figure 5) was also studied. The results are also shown in Figure 4, red pathway. Note that the alkyl-Co(III) 55 compound resulting from the head-to-head coupling (containing a $\mathrm{Co}-\mathrm{CH}_{2}$ bond) is slightly more stable than the isomeric compound resulting from the regular head-to-tail coupling (containing a $\mathrm{Co}-\mathrm{CHCl}$ bond). This leads to an even slightly greater energy for the $\beta-\mathrm{H}$ elimination process starting 60 from this dormant species ( $23 \mathrm{kcal} / \mathrm{mol}$, Figure 4$)$. Clearly, a $\beta$-H elimination process cannot explain the observed interruption of chain growth.

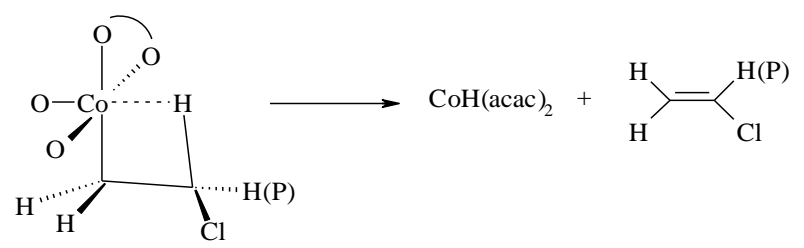

Figure 5. $\beta$-H elimination from PVC-Co(acac $)_{2}$ dormant chain (head-to-head addition).

A second hypothesis to account for the premature stop of the polymerization invokes the formation of a stronger C-Co bond at the PVC chain-end as a consequence of the head-to-head 70 coupling. Therefore, the homolytic bond dissociation energy (BDE) of the $\mathrm{C}-\mathrm{Co}(\mathrm{acac})_{2}$ bond for the two above mentioned models of the dormant chain has been calculated by DFT. Table 3 shows that the bond made by $\mathrm{Co}(\mathrm{acac})_{2}$ with the more reactive $\mathrm{CH}_{2} \mathrm{Cl}-\mathrm{CH}_{2} \bullet$ radical is ca. $4.8 \mathrm{kcal} / \mathrm{mol}$ stronger than 75 that made with the less reactive $\mathrm{CH}_{3} \mathrm{CHCl} \bullet$ radical. The (acac) ${ }_{2} \mathrm{Co}-\mathrm{CH}_{2} \mathrm{CH}_{2} \mathrm{Cl}(\mathrm{BDE}=9.8 \mathrm{kcal} / \mathrm{mol}$, Table 3 entry 1$)$, might be strong enough to prevent further polymerization. This value should be compared with those calculated for the 
(acac) $)_{2} \mathrm{Co}-\mathrm{CH}\left(\mathrm{OOCCH}_{3}\right) \mathrm{CH}_{3}$ bond in the monodentate (5.7 $\mathrm{kcal} / \mathrm{mol}$, entry 3$)$ and $\left(\kappa^{2}: C, O\right)$-bidentate $(11.9 \mathrm{kcal} / \mathrm{mol}$, entry 4) modes..$^{51,55}$ In the presence of donating ligands such as DMF or DMSO, the first mode is adopted and sustained 5 polymerization is experimentally observed, whereas in the absence of ligands the second mode is adopted and this system is not able to generate radical at room temperature (the ligandfree bulk polymerization can only take place by degenerate transfer). The fact that the (acac) ${ }_{2} \mathrm{Co}-\mathrm{CH}_{2} \mathrm{CH}_{2} \mathrm{Cl} \mathrm{BDE}$ value is 10 only slightly below that estimated for the inert (acac) ${ }_{2} \mathrm{Co}-\mathrm{PVAc}$ dormant species could lend some credence to this hypothesis. Head-to-head addition is a reasonable hypothesis to explain the polymerization inhibition when considering the head-to-head additions extent compared to the head-to-tail one $(1 \%)^{64}$ and 15 the degree of polymerization reached ( $\mathrm{DP}=210-550$; Table 2 ).

Table 3. DFT calculated bond dissociation enthalpies (BDE) at 298K for different R-Co(acac $)_{2}$ complexes

\begin{tabular}{clcc}
\hline Entry & \multicolumn{1}{c}{$\mathbf{R}$} & $\begin{array}{c}\text { BDE } \\
(\mathbf{k c a l} / \mathbf{m o l})\end{array}$ & References \\
\hline 1 & $\mathrm{CH}_{2} \mathrm{ClCH}_{2}-$ & 9.8 & This work \\
2 & $\mathrm{CH}_{3} \mathrm{CHCl}^{-}$ & 5.0 & This work \\
3 & $\mathrm{CH}_{3}\left(\mathrm{CH}_{3} \mathrm{COO}\right) \mathrm{CH}-$ & 5.7 & 50,54 \\
4 & $\begin{array}{l}\mathrm{CH}_{3}\left(\mathrm{CH}_{3} \mathrm{COO}\right) \mathrm{CH}- \\
\left(\kappa^{2}: C, O\right)-\end{array}$ & 11.9 & 50,54 \\
\hline
\end{tabular}

Calculations carried out using the B3LYP basis
The last reasonable hypothesis to explain why the $\mathrm{VC}$ polymerization stops at low monomer conversion is the occurrence of extensive irreversible termination reactions at the early stages of the polymerization, accumulating $\mathrm{Co}(\mathrm{acac})_{2}$ in 25 the medium. Provided that this $\mathrm{Co}(\mathrm{acac})_{2}$ excess is high enough, the equilibrium between active and dormant chains would be strongly shifted towards the dormant species, leading to a strong slowing down of the polymerization and, eventually, to its inhibition. Incidentally, this hypothesis would also 30 rationalize the low initiator efficiency factors, in the $0.47-0.68$ range (see Table 2).

To tentatively control the VC polymerization by the alkylCo(III) compound, we decided to work under non-isotherm conditions with a temperature ramp of $0.12^{\circ} \mathrm{C} \mathrm{min}^{-1}$ from 40 to ${ }_{35} 80^{\circ} \mathrm{C}$ (Table 4). Surprisingly, the molar masses increase with time and thus with the temperature (Table 4 and Figure 6). From about $65^{\circ} \mathrm{C}(5 \mathrm{~h}$ of polymerization), the experimental molecular weight becomes lower than the theoretical one (Table 4, entries 3 and 4), namely $\mathrm{f}>1$. This is rationalized by 40 the occurrence of a greater degree of chain transfer reactions at higher temperature. At that point, we observed an overheat phenomenon into the reactor, where the temperature was about $10^{\circ} \mathrm{C}$ higher than the temperature set. This phenomenon is explained by a smooth loss of polymerization control due to the 45 weakness of the C-Co bond at the PVC chain-end at this temperature. The excess calories generated by the exothermic polymerization are the source of this overheating, because they are not efficiently dissipated in bulk polymerizations. This phenomenon certainly contributes to the occurrence of chain 50 transfer reactions (transfer to monomer and to polymer), which are temperature dependent.

20

Table 4. VC bulk polymerization initiated by the alkyl-Co(III) compound under non-isotherm conditions using a temperature ramp of $0.12^{\circ} \mathrm{C}$ min ${ }^{-1}$.

\begin{tabular}{|c|c|c|c|c|c|c|c|}
\hline Entry & $\begin{array}{l}\text { Polym time \& } \\
\text { temperature }\end{array}$ & $\underset{\text { (a) }}{\mathrm{VC} \text { conv }}$ & $\frac{\text { Mn th }}{(\mathrm{g} / \mathrm{mol})}$ & $\begin{array}{c}\text { Mn SEC } \\
\text { DMF-LiBr } \\
\left(_{(\mathrm{g} / \mathrm{mol})}{ }^{(c)}\right.\end{array}$ & $\begin{array}{c}\text { Mw/Mn } \\
\text { SEC DMF- } \\
\text { LiBr }^{(c)}\end{array}$ & $\begin{array}{c}\text { Mn } \\
\text { MALLS } \\
(\mathrm{g} / \mathrm{mol})^{(\mathrm{d})}\end{array}$ & $\begin{array}{l}\mathbf{f} \\
\text { (e) }\end{array}$ \\
\hline$\underset{\text { (f) }}{\mathbf{R E F}}$ & $6 \mathrm{~h} 00$ at $40^{\circ} \mathrm{C}$ & $59 \%$ & l & 68200 & 2.13 & 56000 & I \\
\hline 1 & $1.5 \mathrm{~h}=$ stop at $40^{\circ} \mathrm{C}$ & $7 \%$ & 13400 & 23700 & 2.51 & 23500 & 0.57 \\
\hline 2 & $3 \mathrm{~h}=$ stop at $51^{\circ} \mathrm{C}$ & $8 \%$ & 15400 & 28600 & 2.62 & 29400 & 0.52 \\
\hline 3 & $5 \mathrm{~h}=$ stop at $65^{\circ} \mathrm{C}$ & $22 \%$ & 42200 & 37000 & 2.21 & 38300 & 1.10 \\
\hline 4 & $7 \mathrm{~h}=$ stop at $80^{\circ} \mathrm{C}$ & $34 \%$ & 65200 & 44000 & 2.27 & 47100 & 1.38 \\
\hline
\end{tabular}

Conditions: bulk polymerization of $\mathrm{VC}$ initiated by $2 \mathrm{ml}$ of $1.5633 \times 10^{-1} \mathrm{~mol} / \mathrm{L}$ alkyl-Co (III) solution under non-isotherm conditions with [VC]/ [alkyl$\left.{ }_{55} \mathrm{Co}(\mathrm{III})\right]=3250 / 1$ with a temperature ramp of $0.12^{\circ} \mathrm{C} \mathrm{min}^{-1}$.

(a) Calculated gravimetrically after precipitation of the sample in cold heptane; (b) Calculated on the basis of VC conversion and the cobalt concentration; (c) obtained by SEC in DMF-LiBr, with a PMMA calibration; (d) SEC analysis with MALLS detection, in DMF-LiBr where dn/dc = 0.0793; (e) efficiency factor $\mathrm{f}=\mathrm{Mn}$ th $/ \mathrm{Mn}$ exp; (f) VC free-radical polymerization in bulk at $40^{\circ} \mathrm{C}$ initiated by V-70; [VC]/[V-70] $=643 / 1$. 


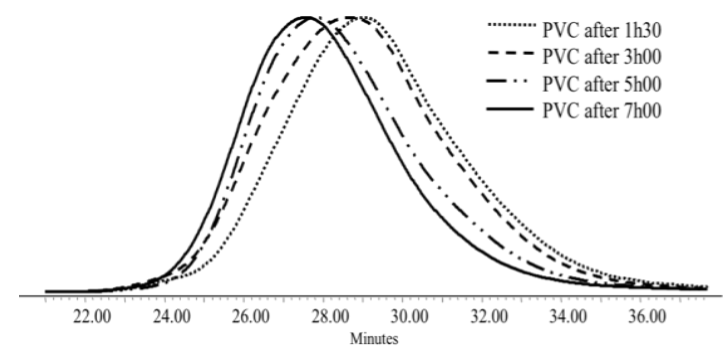

Figure 6. SEC chromatograms obtained during the bulk VC polymerization initiated by the alkyl-Co(III) adduct under nonisotherm conditions (temperature ramp: $0.12^{\circ} \mathrm{C} /$ minute) with $[\mathrm{VC}] /$ [alkyl-Co (III)] = 3250/1.

In conclusion, our preliminary studies show that the VC polymerization presents some characteristic features of a controlled process when initiated by the alkyl-Co(III) compound under non-isotherm conditions that were never 10 tested before for CMRP. The PVC molecular weight increases with the monomer conversion when the polymerization temperature is gently increased. This observation is in sharp contrast with the conventional VC polymerization in which $\mathrm{Mn}$ decreases with the temperature, ${ }^{59-60}$ due to the occurrence of 15 transfer reactions that are more greatly favored at higher temperatures (Figure 7).

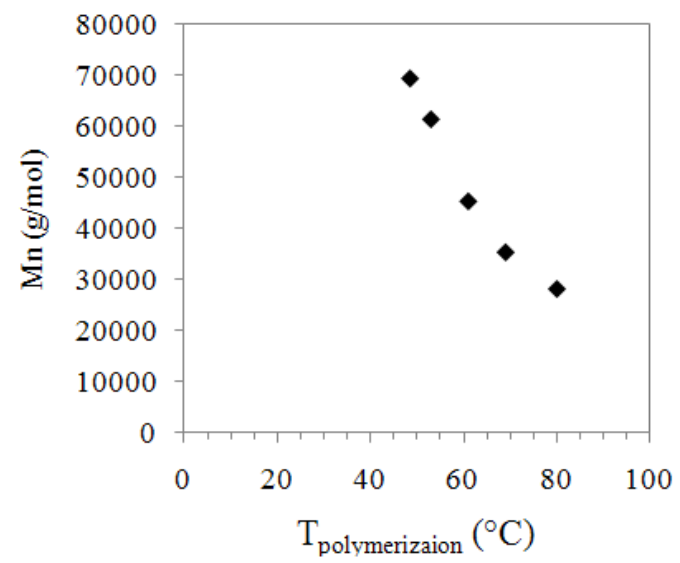

Figure 7. Evolution of the absolute molecular weight of PVC synthesized by free radical polymerization of VC versus the polymerization temperature. Confidential polymerization conditions, SolVin data.

An hypothesis to explain the above-mentioned observation could be to consider a chain-reactivation approach. Increasing the polymerization temperature should not only reactivate the 25 dormant chains favoured by the accumulation of the cobalt complex, but also reactivate the $\mathrm{C}$-Co bond of the stronger $\mathrm{CH}_{2} \mathrm{Cl}-\mathrm{CH}_{2}-\mathrm{Co}$ (acac) 2 chain-end resulting from the head-tohead addition discussed above. Therefore, by increasing the temperature, the dormant/active species equilibrium should be 30 slightly shifted towards the active ones, with the excess of cobalt complex that should allow the regulation of the polymerization at this temperature.

PVC microstructure investigation. As discussed in the 35 introduction, $\mathrm{VC}$ is characterized by one of the largest transfer constant to monomer $\left(\mathrm{C}_{\mathrm{M}}\right)$ among all the conventional monomers (i.e. $22 \times 10^{-4}$ at $\left.50{ }^{\circ} \mathrm{C}\right) .^{4}$ This limits the PVC maximum molecular weight that can be obtained by free radical polymerization of $\mathrm{VC}$ at a given temperature ${ }^{65}$, the chain 40 transfer to monomer being temperature dependent and practically independent of the initiator concentration. ${ }^{59,60,65}$ This large $\mathrm{C}_{\mathrm{M}}$ affects the $\mathrm{PVC}$ microstructure, since transfer reactions occur during the polymerization and cause the formation of defects. The structural defects can be determined 45 and estimated by NMR spectroscopy, this method allowing characterizing and quantifying the anomalous units along the polymer chain. ${ }^{66-75}$

A head-to-head addition is believed to be at the origin of the transfer reactions (Scheme 2). ${ }^{59-60}$ Transfer to monomer is the 50 main transfer reaction observed during $\mathrm{VC}$ polymerization and results in the formation of $-\mathrm{CH}=\mathrm{CH}-\mathrm{CH}_{2} \mathrm{Cl}$ chain ends as the major structural defect.

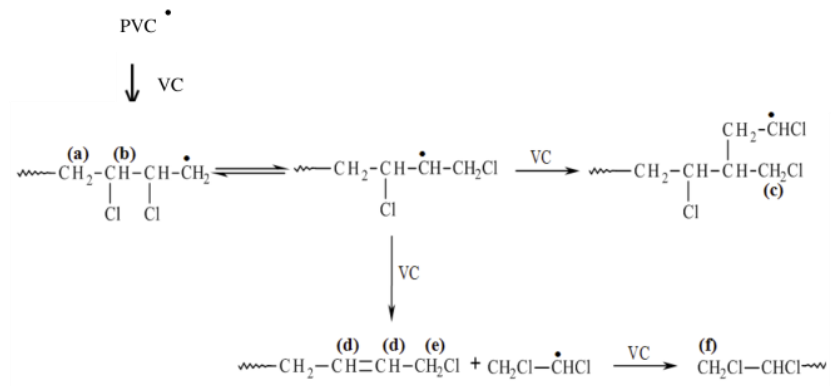

55 Scheme 2. Formation of microstructural defects in PVC due to transfer reactions occurring during $\mathrm{VC}$ polymerization.

To evaluate the impact of using $\mathrm{Co}(\mathrm{acac})_{2}$ on the PVC microstructure, some of our PVC samples were analysed by ${ }^{1} \mathrm{H}$ ${ }_{60} \mathrm{NMR}$ spectroscopy. It is important to mention that the preparation of samples for the NMR analysis is challenging. Indeed, the free cobalt complex $\left(\mathrm{Co}(\mathrm{acac})_{2}\right)$ is paramagnetic and must be eliminated prior to NMR analysis. This is realized by the addition of excess TEMPO at the end of the 65 polymerization, leading to irreversible end-capping of the polymer chain by the nitroxyl radical and to the release of $\mathrm{Co}(\mathrm{acac})_{2}{ }^{38}$ Several steps of precipitations and purifications on silica were necessary to remove most of the contaminants and to allow recording satisfactory ${ }^{1} \mathrm{H}$ NMR spectra.

$70 \mathrm{PVC}$ samples synthesized by free radical polymerization at $40^{\circ} \mathrm{C}$ in bulk (V70 as initiator) and at $80^{\circ} \mathrm{C}$ in suspension (confidential initiator) were considered as references. We only investigated the $-\mathrm{CH}=\mathrm{CH}-\mathrm{CH}_{2} \mathrm{Cl}$ structural defect, which is the most representative one for transfer to monomer and is easily 75 detected. Comparison of the signal intensities of the polymer backbone hydrogen atom $-\mathrm{CH}_{2} \mathrm{CHCl}-(4.2-4.8 \mathrm{ppm})$ and the hydrogen atoms of the $-\mathrm{CH}=\mathrm{CH}-\mathrm{CH}_{2} \mathrm{Cl}$ defect structure $(4.1$ ppm for $\mathrm{CH}_{2}$ (e, scheme 2) and 5.8 ppm for $\mathrm{CH}=\mathrm{CH}$ (d, scheme 2)) allows quantifying the defect in the PVC sample. The ${ }_{80} \mathrm{CH}_{2} \mathrm{CHCl}-/-\mathrm{CH}=\mathrm{CH}-\mathrm{CH}_{2} \mathrm{Cl}$ molar ratio is $1000 / 0.56$ at $40^{\circ} \mathrm{C}$ and $1000 / 2$ at $80^{\circ} \mathrm{C}$.

The PVC prepared by VC polymerization initiated by the alkylCo(III) compound under non-isotherm conditions (Table 4, entry 4) was then analysed and compared to the references. The 
polymerization was carried out during 7 hours, after which the temperature reached $80^{\circ} \mathrm{C}$. Figure 8 shows that the structural defect at $4.1 \mathrm{ppm}$ and $5.8 \mathrm{ppm}$ is present with a $-\mathrm{CH}_{2} \mathrm{CHCl}-/-$ $\mathrm{CH}=\mathrm{CH}-\mathrm{CH}_{2} \mathrm{Cl}$ molar ratio of $1000 / 2$. This amount of defects ${ }_{5}$ is similar to that of the reference obtained at $80^{\circ} \mathrm{C}$. On the basis of this analysis, $\mathrm{Co}(\mathrm{acac})_{2}$ does not seem to decrease nor increase significantly the level of defects on PVC.

For the sake of comparison, the level of defects that we observe in our PVC produced under these non-isotherm conditions is in 10 the same range as for the PVC produced by SET-DTLRP process at lower temperature $\left(25^{\circ} \mathrm{C}\right) .{ }^{27,69,76}$

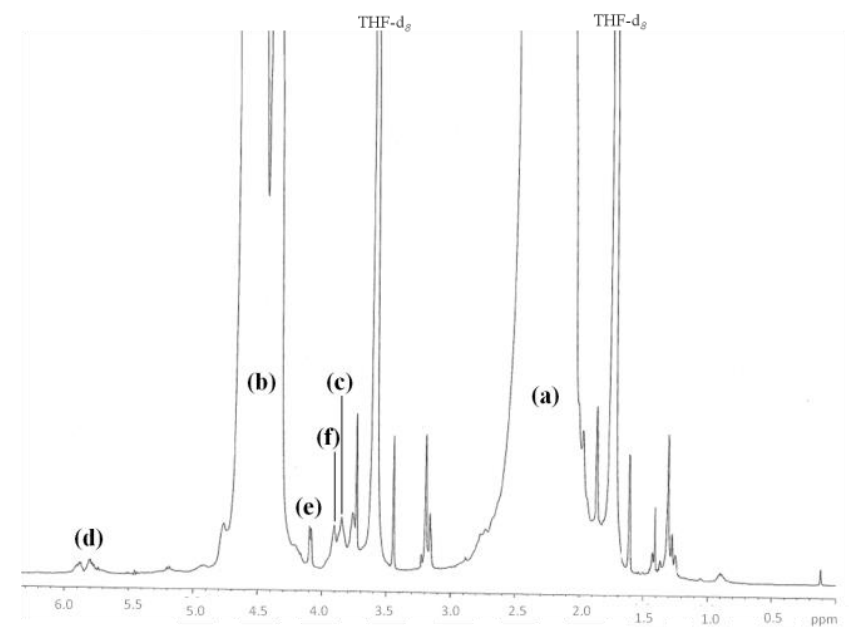

Figure 8. ${ }^{1} \mathrm{H}$ NMR spectra in THF- $\mathrm{d}_{8}$ of PVC prepared by CMRP initiated by the alkyl-Co(III) compound under non-isotherm conditions (table 4, entry 4).

Bulk VC/VAc statistical copolymerization by CMRP. The transfer reactions, experienced in the VC homopolymerization 20 at high temperatures might be prevented by copolymerizing VC with VAc, since the latter presents a better coupling efficiency with the cobalt complex. Indeed, the same challenge was already faced in the case of acrylates, where the use of $\mathrm{Co}(\mathrm{acac})_{2}$ under conditions identical to those of the VAc 25 polymerization did not exert any control. The high lability of the C-Co bond at the polyacrylate chain-end was responsible for this effect. ${ }^{77}$ However, addition of VAc to the acrylate polymerization resulted in a great improvement, provided its presence in significant amounts (at least $25 \mathrm{~mol} \%)^{77}$ 30 Therefore, we investigated by analogy the effect of VAc addition on the $\mathrm{Co}(\mathrm{acac})_{2}$ - promoted VC polymerization under various conditions.

We first investigated the VC/VAc statistical copolymerization initiated by $\mathrm{V}-70$ in the presence of $\mathrm{Co}(\mathrm{acac})_{2}$ $35\left([\mathrm{~V} 70] /\left[\mathrm{Co}(\mathrm{acac})_{2}\right]=1 / 1\right)$. A low VC/VAc molar ratio is expected to favor the deactivation by the chain-end VAc radical. However, three VC/VAc molar ratios with increasing VC contents were investigated (33:67, 60:40 and 82:18) and the results compared to those obtained for the conventional free 40 radical copolymerization initiated by $\mathrm{V}-70$ in the absence and in the presence of $\mathrm{Co}(\mathrm{acac})_{2}$ as the references (Table 5).

$[\mathrm{VC}] /[\mathrm{VAc}]=33 / 67$
In contrast to the copolymerization carried out by the $\mathrm{V}$ $4570 / \mathrm{Co}(\mathrm{acac})_{2}$ mixture, a regular increase of the monomers conversion with the polymerization time (table 5; entries 1-3) was observed when the copolymerization was initiated by the alkyl-cobalt(III) at $40^{\circ} \mathrm{C}$. Moreover, a high VC conversion (79 $\%$ ) was reached after $6 \mathrm{~h}$ of reaction. Importantly, the 50 molecular weight of the resulting copolymer increased with the comonomer conversion with a very good agreement between the theoretical and the experimental molecular weights. These data suggest that each alkyl-Co(III) initiates the polymerization of one polymer chain and that the latter continuously grows 55 during the whole polymerization process. The SEC chromatograms of the copolymers are monomodal and clearly shifted towards the higher molecular weight side with the monomer conversion (Figure 9A), in line with a controlled process. The polydispersity is however increasing with the ${ }_{60}$ polymerization time due to some tailing observed at the low molecular weight side of the SEC chromatogram. This lailing might be the result of some termination reactions. For the sake of comparison, when the copolymerization was carried out by conventional free radical polymerization using V-70 in the 65 absence of $\mathrm{Co}(\mathrm{acac})_{2}$, no significant molecular weight evolution was observed (Table 5, entries 4-6; Figure 9B). In the presence of $\mathrm{Co}(\mathrm{acac})_{2}$, no polymerization was observed after 6 $\mathrm{h}$ of reaction (Table 5, entries 7-8), most probably due to a long induction period $\left(>6 \mathrm{~h}\right.$ ) as observed in the CMRP of VAc. ${ }^{37}$

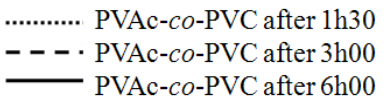

(A)

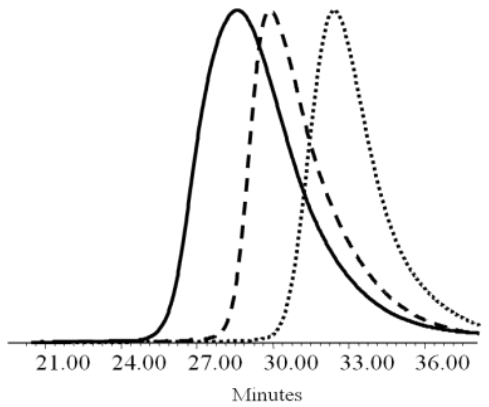

$75(\mathrm{~B})$

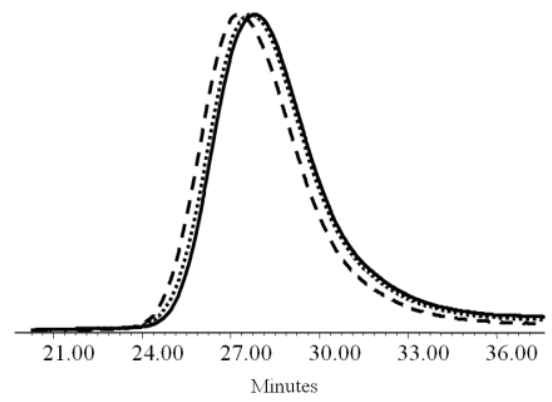

Figure 9. SEC chromatograms obtained for the VC/VAc copolymerization, $[\mathrm{VC}] /[\mathrm{VAc}]=33 / 67$, bulk, $40^{\circ} \mathrm{C}$, initiated by $(\mathrm{A})$ 
Table 5. Results of VC/VAc statistical copolymerization with low VC content using alkyl-Co(III) or V70 at $40^{\circ} \mathrm{C}$

\begin{tabular}{|c|c|c|c|c|c|c|c|c|c|c|c|c|c|}
\hline Entry & $\begin{array}{c}\text { Polym } \\
\text { time }\end{array}$ & Initiator & $\begin{array}{c}\text { VC/VAc } \\
\text { copolymer } \\
\text { composition } \\
\text { (a) }\end{array}$ & $\begin{array}{c}\text { VC } \\
\text { Conv } \\
\text { (b) }\end{array}$ & $\begin{array}{l}\text { VAc } \\
\text { conv } \\
\text { (b) }\end{array}$ & $\begin{array}{l}\text { Mn th. } \\
\underset{(\mathrm{g} / \mathrm{mol})}{(\mathrm{c})}\end{array}$ & $\begin{array}{c}\text { Mn } \\
{ }^{1} \mathbf{H ~ N M R} \\
(\mathrm{g} / \mathrm{mol})^{(\mathrm{d})}\end{array}$ & $\begin{array}{c}\text { Mn } \\
\text { MALLS } \\
(\mathrm{g} / \mathrm{mol})^{(\mathrm{e})}\end{array}$ & $\begin{array}{c}\text { Mn } \\
\underset{(\mathrm{gEC} \mathrm{DMFl})^{(\mathrm{f})}}{(\mathrm{m}}\end{array}$ & $\begin{array}{c}\text { Mw/Mn } \\
\text { SEC } \\
\text { DMF }\end{array}$ & $\mathbf{f}^{(\mathrm{g})}$ & $\begin{array}{c}\text { Tg } \\
\text { th. } \\
\left(\begin{array}{l}\circ \\
(\text { C) }\end{array}\right)\end{array}$ & $\begin{array}{l}\text { Tg } \\
\text { exp. } \\
\left({ }^{\circ} \mathrm{C}\right)\end{array}$ \\
\hline 1 & $1.5 \mathrm{~h}$ & Alkyl-Co(III) & $59 / 41$ & $14 \%$ & $5 \%$ & 8100 & 10200 & 9600 & 11200 & 1.27 & 0.84 & 46 & 32 \\
\hline 2 & $3 \mathrm{~h}$ & Alkyl-Co(III) & $62 / 38$ & $32 \%$ & $12 \%$ & 21200 & 22100 & 21500 & 21700 & 1.55 & 0.99 & 48 & 50 \\
\hline 3 & $6 \mathrm{~h}$ & Alkyl-Co(III) & $50 / 50$ & $79 \%$ & $44 \%$ & 61100 & 1 & 56000 & 39100 & 2.18 & 1.09 & 43 & 48 \\
\hline 4 & $1.5 \mathrm{~h}$ & $\mathrm{~V}-70$ & $60 / 40$ & $19 \%$ & $6 \%$ & 1 & 7 & 47500 & 46700 & 2.15 & 1 & nd & nd \\
\hline 5 & $3 \mathrm{~h}$ & $V-70$ & $61 / 39$ & $53 \%$ & $16 \%$ & I & I & 68800 & 52100 & 2.26 & I & nd & nd \\
\hline 6 & $6 \mathrm{~h}$ & V-70 & $63 / 37$ & $58 \%$ & $17 \%$ & l & l & 59100 & 44200 & 2.08 & l & nd & nd \\
\hline 7 & $3 \mathrm{~h}$ & $\mathrm{~V}-70+\mathrm{Co}(\mathrm{acac})_{2}$ & 1 & $0 \%$ & $0 \%$ & I & I & 1 & 1 & 1 & I & nd & nd \\
\hline 8 & $6 \mathrm{~h}$ & $\mathrm{~V}-70+\mathrm{Co}(\mathrm{acac})_{2}$ & l & $0 \%$ & $0 \%$ & I & I & I & I & I & I & nd & nd \\
\hline
\end{tabular}

${ }_{5}$ Conditions : $[\mathrm{VC}] /[\mathrm{VAc}]=33 / 67$, bulk, $40^{\circ} \mathrm{C}$ with $[$ alkyl-Co(III) $/([\mathrm{VC}]+[\mathrm{VAc}])=1 / 1400$ for entries 1,2 and 3 ; with $[\mathrm{V} 70] /([\mathrm{VC}]+[\mathrm{VAc}])=1 / 1400$ for entries 4, 5 and 6; and with $\left[\mathrm{Co}(\mathrm{acac})_{2}\right] /[\mathrm{V}-70] /([\mathrm{VC}]+[\mathrm{VAc}])=1 / 1 / 1400$ for entries 7 and 8.

(a) Composition in each monomer in the PVC-co-PVAc copolymer calculated by ${ }^{1} \mathrm{H}$ NMR; (b) Conversion calculated on the basis of the composition and the total mass of the obtained copolymer, as described in the Experimental section; (c) $\mathrm{Mn}_{\mathrm{th}}$ calculated for each monomer by : $\mathrm{Mn}_{\mathrm{th}}=\left(\left(\mathrm{m}_{\mathrm{VC}} \mathrm{x} \mathrm{VC}\right.\right.$ conv $)+$ $\left(\mathrm{m}_{\mathrm{VAc}} \mathrm{x} \mathrm{VAc}\right.$ conv $\left.)\right) / \mathrm{n}(\mathrm{Co})$, where $\mathrm{m}_{\mathrm{VC}}=$ initial VC mass, $\mathrm{m}_{\mathrm{VAc}}=$ initial VAc mass and $\mathrm{n}(\mathrm{Co})=$ alkyl-Co(III) mol quantity; (d) $\mathrm{Mn}_{\mathrm{exp}}$ calculated by ${ }^{1} \mathrm{H}-$

$10 \mathrm{NMR}$ by comparison of the intensities of signal corresponding to the polymer backbone $\left(\mathrm{CH}_{2}-\mathrm{C}-\mathrm{H}-\mathrm{OCOCH} 3\right.$ of $\mathrm{PVAc}($ at $4.8-5.5 \mathrm{ppm}), \mathrm{CH}-\mathrm{CH}-\mathrm{Cl}$ of PVC (at 3.8-4.7 ppm)) and the $\alpha$ chain-end $\left(-\mathrm{OCH}_{3}\right)$ at $3.1 \mathrm{ppm}$; (e) absolute molecular weight determined by SEC analysis with MALLS detection, in DMF-LiBr and with dn/dc measured for each sample; (f) SEC in DMF-LiBr with RI detection, calibration with PMMA; (g) initiator efficiency factor f = $\mathrm{Mn}_{\mathrm{th}} / \mathrm{Mn}_{\text {exp }}$; (f) Theoretical Tg calculated by $1 / \mathrm{Tg}_{\text {PVC-co-PVAc }}=\left(\mathrm{W}_{\mathrm{PVC}} / \mathrm{Tg}_{\mathrm{PVC}}\right)+\left(\mathrm{W}_{\mathrm{PVAc}} / \mathrm{Tg}_{\mathrm{PVAc}}\right)$, where $\mathrm{W}=$ weight fraction of one monomer in the copolymer, measured $\mathrm{Tg}_{, \mathrm{PVC}}=81^{\circ} \mathrm{C}$, measure $\mathrm{Tg}_{, \mathrm{PVAc}}=32^{\circ} \mathrm{C}$. nd: not determined.

$$
15
$$

The ${ }^{1} \mathrm{H}$ NMR analysis of the copolymer prepared by CMRP evidences the presence of the typical PVAc and PVC signals (Figure 10). The composition of the copolymer was determined by comparison of the intensities of the PVAc $\mathrm{CH}_{2}-\mathrm{C}_{-}-$ ${ }_{20} \mathrm{OCOCH}_{3}$ (at $4.8-5.5 \mathrm{ppm}$ ) and $\mathrm{PVC} \mathrm{CH}_{2}-\mathrm{CH}-\mathrm{Cl}$ (at 3.8-4.7 ppm) signals. As expected for a statistical copolymer, the peak between $4.3 \mathrm{ppm}$ and $4.7 \mathrm{pm}$ are assigned to the $\mathrm{VC}$ moieties adjacent to the VAc moieties.

Table 5 (entries 1-3) clearly shows that the VC incorporation in 25 the polymer is greater than that of VAc, in agreement with the monomer reactivity ratios in favor of $\mathrm{VC}(\mathrm{rvC}=2$ and $\mathrm{rvAc}=$ $0.2){ }^{78-80}$

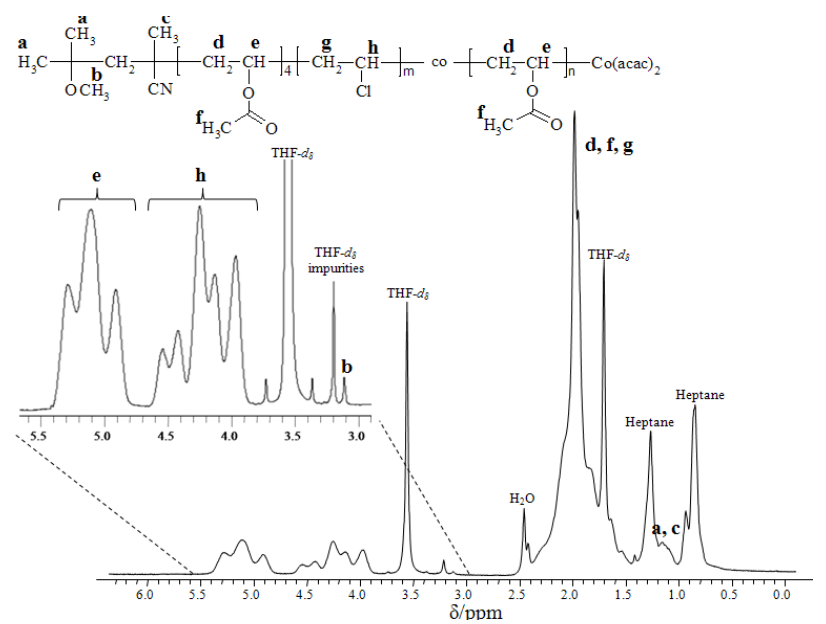

Figure 10. ${ }^{1} \mathrm{H}$ NMR spectrum in THF- $\mathrm{d}_{8}(400 \mathrm{MHz})$ of PVC-co-PVAc 30 synthesized from alkyl-Co(III) in bulk at $40^{\circ} \mathrm{C}$ (table 3 , entry 3 ).

On figure 10 , the signal at $3.2 \mathrm{ppm}$ is attributed to the $-\mathrm{OC} \underline{H}_{3}$ group of the V-70 fragment and is thus located at the $\alpha$ chain- end of the polymer. Consequently, comparison of the intensities of this signal with those corresponding to the 35 polymer backbone allows calculating the copolymer molecular weight (Mn NMR, Table 5, entries 1 and 2), which is in very good agreement with that determined by SEC MALLS. This is additional evidence that most of the polymer chains are initiated by alkyl-Co(III) and remain controlled during the 40 whole polymerization process.

Differential scanning calorimetry (DSC) analysis allows measuring the samples glass transition temperature $(\mathrm{Tg})$. These Tg's are compared to the theoretical ones calculated on the basis of the composition of each monomer and the Tg of PVC ${ }_{45}\left(81^{\circ} \mathrm{C}\right)$ and PVAc $\left(32^{\circ} \mathrm{C}\right)$. The good agreement between the experimental $\mathrm{Tg}$ values of the copolymer synthesized using alkyl-cobalt(III) with the theoretical one (Table 5, entries 1, 2 and 3) confirms the compositions. Note that the copolymer obtained after 1 h30 reaction has an experimental $\mathrm{Tg}$ much 50 lower than the theoretical one $\left(32^{\circ} \mathrm{C}\right.$ vs $\left.46^{\circ} \mathrm{C}\right)$. This difference is explained by the molar mass of this sample that is relatively low (less than $10000 \mathrm{~g} / \mathrm{mol}$ ), since the glass transition temperature is affected by the polymer molecular weight.

${ }_{55}[\mathrm{VC}] /[\mathrm{VAc}]=\mathbf{6 0} / \mathbf{4 0}$, and 82/18. The vinyl chloride content was then increased in the polymerization medium in order to determine the maximum amount of VC tolerated by the system. Using a [VC]/[VAc] ratio of 60/40 (table 6, entries 1-3), the comonomers conversion increased with the reaction time and ${ }_{60}$ the VC conversion is still higher than that of VAc, in agreement with the reactivity ratios. On the other hand, the conversion after $6 \mathrm{~h}$ (Table 6 , entry 3 ) is lower than for the experiment described above with higher VAc content (Table 5, entry 3). Importantly, the molecular weight increases with 
monomer conversion, with absolute values in good agreement with the theoretical ones, in line with a controlled process. SEC chromatograms clearly shift towards lower elution volumes (higher molecular weights) as the polymerization progresses 5 (Figure 11a), supporting the controlled growth of the polymer chains until at least $6 \mathrm{~h}$ of polymerization.

When the VC/VAc molar ratio was further increased $([\mathrm{VC}] /[\mathrm{VAc}]=82 / 18)$, the control seems to be (partly) lost as evidenced by absolute molecular weights twice higher than the 10 theoretical values, suggesting that only $50 \%$ of the alkylcobalt(III) adduct initiated polymer chains. Moreover, Figure 11c clearly shows that the SEC chromatograms do not greatly shift with the monomer conversion. The small shoulder observed on the chromatogram at the higher molecular weight 15 side after $6 \mathrm{~h}$ of reaction might be due to the occurrence of some coupling reactions. These side reactions might therefore account for the Mn increase in the last sample (40 $800 \mathrm{~g} / \mathrm{mol})$. Finally, the monomer conversions are low after $6 \mathrm{~h}(21 \%$ for $\mathrm{VC}$ and $9 \%$ for VAc) and are twice lower than in the previous 20 experiment. Clearly, increasing the VC content in the polymerization medium is not beneficial to the polymerization control. As predicted by the reactivity ratios, $\mathrm{VC}$ is preferentially incorporated in the copolymer.

The experimental glass transition temperatures are also in good 25 agreement with the theoretical ones (Table 6), in line with the copolymer composition.

Table 6. Results for the VC/VAc statistical copolymerization with higher vinyl chloride content

\begin{tabular}{|c|c|c|c|c|c|c|c|c|c|c|c|c|c|}
\hline $\begin{array}{c}\text { Entr } \\
\mathbf{y}\end{array}$ & $\begin{array}{l}\text { Polym } \\
\text { time }\end{array}$ & Initiator & $\begin{array}{c}\text { VC/VAc } \\
\text { copolymer } \\
\text { composition }^{(a)}\end{array}$ & $\begin{array}{l}\mathrm{VC} \\
\text { conv } \\
(\mathbf{b})\end{array}$ & $\begin{array}{l}\text { VAc } \\
\text { conv } \\
\text { (b) }\end{array}$ & $\begin{array}{l}\text { Mn th. } \\
\underset{(\mathrm{g} / \mathrm{mol})}{(\mathrm{c})}\end{array}$ & $\begin{array}{c}{ }^{\mathrm{Mn}} \\
{ }^{1} \mathbf{H} \mathrm{NMR} \\
(\mathrm{g} / \mathrm{mol})^{(\mathbf{d})}\end{array}$ & $\begin{array}{c}\text { Mn } \\
\text { MALLS } \\
(\mathrm{g} / \mathrm{mol})^{(\mathrm{e})}\end{array}$ & $\begin{array}{c}\text { Mn } \\
\text { SEC DMF } \\
(\mathrm{g} / \mathrm{mol})^{(\mathrm{f})}\end{array}$ & $\begin{array}{c}\text { Mw/Mn } \\
\text { SEC } \\
\text { DMF }\end{array}$ & $\mathbf{f}^{(\mathrm{g})}$ & $\begin{array}{l}\text { Tg } \\
\text { th. } \\
\left({ }^{\circ} \mathbf{C}\right) \\
\text { (h) }\end{array}$ & $\begin{array}{l}\text { Tg } \\
\text { exp. } \\
\left({ }^{\circ} \mathbf{C}\right)\end{array}$ \\
\hline 1 & $1.5 \mathrm{~h}$ & Alkyl-Co(III) & $83 / 17$ & $18 \%$ & $5 \%$ & 13100 & 15500 & 19400 & 18000 & 1.57 & 0.68 & 61 & 66 \\
\hline 2 & $3 \mathrm{~h}$ & Alkyl-Co(III) & $79 / 21$ & $20 \%$ & $8 \%$ & 17200 & 22200 & 20600 & 21800 & 1.68 & 0.83 & 57 & 58 \\
\hline 3 & $6 \mathrm{~h}$ & Alkyl-Co(III) & $79 / 21$ & $53 \%$ & $21 \%$ & 41800 & I & 40100 & 34200 & 2.28 & 1.04 & 57 & 61 \\
\hline 4 & $1.5 \mathrm{~h}$ & $\mathrm{~V}-70$ & $81 / 19$ & $11 \%$ & $4 \%$ & I & I & 32000 & 34500 & 2.07 & I & nd & nd \\
\hline 5 & $3 \mathrm{~h}$ & $\mathrm{~V}-70$ & $78 / 22$ & $18 \%$ & $7 \%$ & l & / & 38300 & 40900 & 2.12 & l & nd & nd \\
\hline 6 & $6 \mathrm{~h}$ & V-70 & $78 / 22$ & $74 \%$ & $31 \%$ & I & I & 55900 & 48600 & 2.14 & 1 & nd & nd \\
\hline 7 & $1.5 \mathrm{~h}$ & Alkyl-Co(III) & $91 / 9$ & $13 \%$ & $6 \%$ & 12800 & 34400 & 27200 & 24900 & 2.01 & 0.47 & 68 & 68 \\
\hline 8 & $3 \mathrm{~h}$ & Alkyl-Co(III) & $92 / 8$ & $12 \%$ & $5 \%$ & 11700 & 20700 & 21600 & 20600 & 2.23 & 0.54 & 70 & 67 \\
\hline 9 & $6 \mathrm{~h}$ & Alkyl-Co(III) & $92 / 8$ & $21 \%$ & $9 \%$ & 20600 & I & 40800 & 28800 & 2.40 & 0.50 & 70 & 74 \\
\hline 10 & $1.5 \mathrm{~h}$ & $\mathrm{~V}-70$ & $93 / 7$ & $20 \%$ & $8 \%$ & l & I & 46900 & 47600 & 2.16 & I & nd & nd \\
\hline 11 & $3 \mathrm{~h}$ & $\mathrm{~V}-70$ & $92 / 8$ & $42 \%$ & $16 \%$ & I & I & 48100 & 49600 & 2.30 & I & nd & nd \\
\hline 12 & $6 \mathrm{~h}$ & $\mathrm{~V}-70$ & $91 / 9$ & $55 \%$ & $24 \%$ & I & I & 50500 & 49400 & 2.06 & I & nd & nd \\
\hline
\end{tabular}

${ }_{30}$ Conditions : $[\mathrm{VC}] /[\mathrm{VAc}]=60 / 40$, bulk, $40^{\circ} \mathrm{C}$, initiated by the alkylcobalt (III) compound with [alkyl-Co(III)/([VC]+[VAc] $)=1 / 1545$ for entries 1,2 and $3 ;[\mathrm{VC}] /[\mathrm{VAc}]=60 / 40$, bulk, $40^{\circ} \mathrm{C}$, initiated by V-70 with $[\mathrm{V} 70] /([\mathrm{VC}]+[\mathrm{VAc}])=1 / 1545$ for entries 4,5 and $6 ;[\mathrm{VC}] /[\mathrm{VAc}]=82 / 18$, bulk, $40^{\circ} \mathrm{C}$, initiated by the alkylcobalt (III) compound with [alkyl-Co(III)/([VC] $+[\mathrm{VAc}])=1 / 1700$ for entries 7,8 and 9 ; and $[\mathrm{VC}] /[\mathrm{VAc}]=82 / 18$, bulk, $40^{\circ} \mathrm{C}$, initiated by $\mathrm{V}-$ 70 with $[\mathrm{V} 70] /([\mathrm{VC}]+[\mathrm{VAc}])=1 / 1700$ for entries 10,11 and 12 .

(a) Composition in each monomer in the PVC-co-PVAc copolymer calculated by ${ }^{1} \mathrm{H}$ NMR; (b) Conversion calculated on the basis of the composition and 35 the total mass of the obtained copolymer, as described in the Experimental section; (c) $\mathrm{Mn}_{\mathrm{th}}$ calculated for each monomer by : $\mathrm{Mn}_{\mathrm{th}}=\left(\left(\mathrm{m}_{\mathrm{VC}} \mathrm{X} \mathrm{VC}\right.\right.$ conv $)+$ $\left(\mathrm{m}_{\mathrm{VAc}} \mathrm{x}\right.$ VAc conv $\left.)\right) / \mathrm{n}(\mathrm{Co})$, where $\mathrm{m}_{\mathrm{VC}}=$ initial VC mass, $\mathrm{m}_{\mathrm{VAc}}=$ initial VAc mass and $\mathrm{n}(\mathrm{Co})=$ alkyl-Co(III) mol quantity; (d) $\mathrm{Mn}_{\text {exp }}$ calculated by ${ }^{1} \mathrm{H}$ NMR by comparison of the intensities of signal corresponding to the polymer backbone $\left(\mathrm{CH}_{2}-\mathrm{CH}-\mathrm{OCOCH}\right.$ of PVAc (at $\left.4.8-5.5 \mathrm{ppm}\right), \mathrm{CH}-\mathrm{CH}-\mathrm{Cl}$ of PVC (at 3.8-4.7 ppm)) and the $\alpha$ chain-end $\left(-\mathrm{OC}_{3}\right)$ at $3.1 \mathrm{ppm}$; (e) Absolute molecular weight determined by SEC analysis with MALLS detection, in DMF-LiBr and with dn/dc measured for each sample; (f) SEC in DMF-LiBr with RI detection, calibration with PMMA; (g) Initiator efficiency factor $\mathrm{f}=$

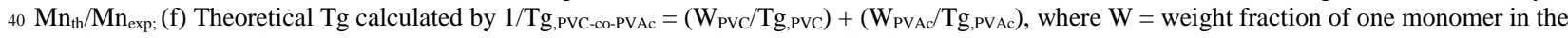
copolymer, measured $\mathrm{Tg}_{\mathrm{PVC}}=81^{\circ} \mathrm{C}$, measure $\mathrm{Tg}_{, \mathrm{PVAc}}=32^{\circ} \mathrm{C}$. nd: not determined

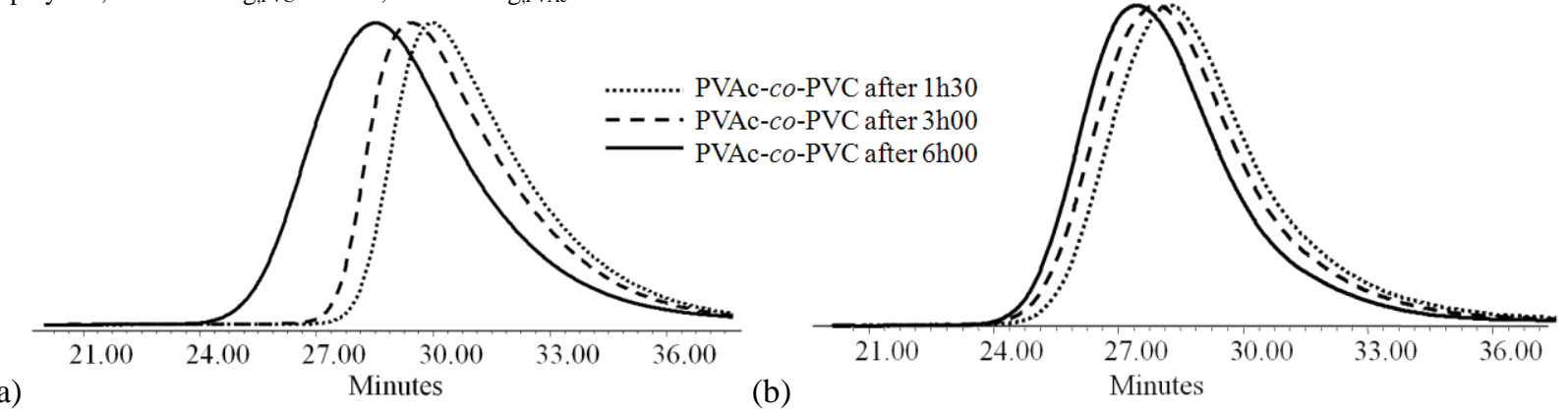




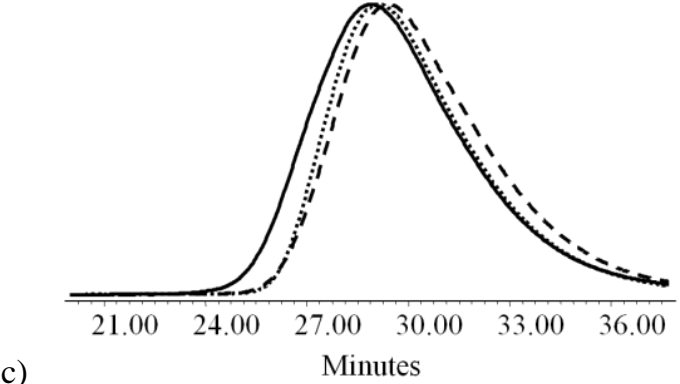

(c)

Minutes

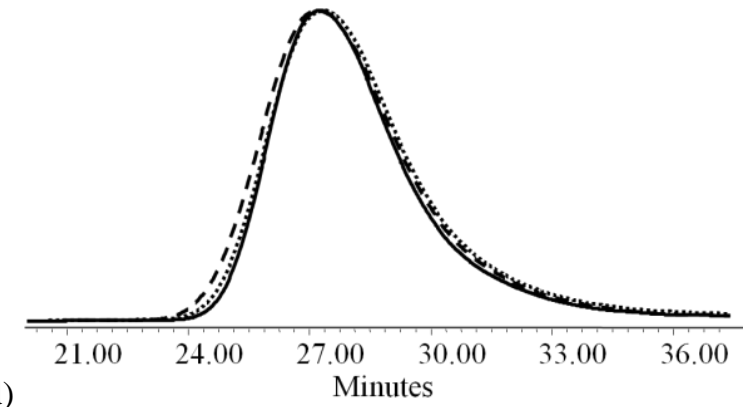

(d)

Figure 11. SEC chromatograms obtained during the VC/VAc statistical copolymerization. Conditions: a. $[\mathrm{VC}] /[\mathrm{VAc}]=60 / 40$, bulk, $40^{\circ} \mathrm{C}$, initiated 5 by the alkylcobalt(III) compound with [alkyl-Co(III)/([VC] $+[\mathrm{VAc}])=1 / 1545 ;$ b. $[\mathrm{VC}] /[\mathrm{VAc}]=60 / 40$, bulk, $^{\circ} 0^{\circ} \mathrm{C}$, initiated by $\mathrm{V}-70$ with $[\mathrm{V} 70] /([\mathrm{VC}]+[\mathrm{VAc}])=1 / 1545 ;$ c. $[\mathrm{VC}] /[\mathrm{VAc}]=82 / 18$, bulk, $40^{\circ} \mathrm{C}$, initiated by the alkylcobalt (III) compound with [alkyl-Co(III) $/([\mathrm{VC}]+[\mathrm{VAc}])=$ $1 / 1700$; $d$. $[\mathrm{VC}] /[\mathrm{VAc}]=82 / 18$, bulk, $40^{\circ} \mathrm{C}$, initiated by V-70 with $[\mathrm{V70}] /([\mathrm{VC}]+[\mathrm{VAc}])=1 / 1700$.

\section{Conclusions}

We have reported herein the first investigation of the CMRP of $10 \mathrm{VC}$. The polymerization was initially carried out at $40^{\circ} \mathrm{C}$ with V70 initiation in the presence of $\mathrm{Co}(\mathrm{acac})_{2}$. On the basis of the polymerization kinetics, $\mathrm{Co}(\mathrm{acac})_{2}$ appeared to be a less efficient trapping agent for the PVC radicals than for the PVAc ones. The DFT calculations have shown that the PVC-Co bond 15 is marginally more labile than the PVAc-Co one $(5.0 \mathrm{kcal} / \mathrm{mol}$ versus $5.7 \mathrm{kcal} / \mathrm{mol}$ and contrary to the acetate group of the PVAc chain, the $\mathrm{Cl}$ atom in the PVC chain cannot stabilize the dormant species by chelation). Under these conditions, the monomer conversion was limited. Then, the VC 20 homopolymerization was initiated by a preformed alkylcobalt(III) in the bulk at $40^{\circ} \mathrm{C}$. Again, inhibition of the polymerization was observed at low monomer conversion. Such a limitation was attributed to the occurrence of irreversible termination reactions during the $\mathrm{VC}$ polymerization 25 with consequent accumulation of the cobalt(II) deactivator in the medium. Subsequent increase of the temperature medium when carried out under non-isotherm conditions with a positive temperature ramp, allowed the $\mathrm{VC}$ homopolymerization to exhibit features of a controlled process, i.e. a molar mass 30 increase with monomer conversion, at least below $60^{\circ} \mathrm{C}$. A preliminary ${ }^{1} \mathrm{H}$ NMR study also indicated that the level of defects of the PVC produced by CMRP is similar to that in PVC prepared by conventional free radical polymerization at the same temperature. Finally, the addition of VAc to the VC

35 polymerization medium had a beneficial effect on the course of the CMRP due to the higher coupling efficiency between $\mathrm{Co}(\mathrm{acac})_{2}$ with the chain end VAc radical. Such copolymerizations were controlled even under isothermal conditions provided that enough VAc ( 40 mol \%) was present 40 in the comonomer feed. High monomer conversions were reached after $6 \mathrm{~h}$ of copolymerization, the experimental molecular weights were in good agreement with the theoretical ones, and the compositions were in line with the reactivity ratios of each monomer, VC being preferentially incorporated. ${ }_{45}$ Given the range of monomers (non-conjugated vinyl monomers such as VAc, VC, N-vinylpyrrolidone, and conjugated ones such as acrylonitrile and acrylates) whose polymerization can be controlled by CMRP, and particularly with $\mathrm{Co}(\mathrm{acac})_{2}$, this work paves the way to the design of unusual PVC based 50 copolymers.

Acknowledgments. The "Belgian Science Policy" in the frame of the "Interuniversity Attraction Poles Programme" (PAI VI/27) and Solvin s.a. are acknowledged for financial support. 55 A.D. (FRS-FNRS Postdoctoral Researcher) and C.D. (FRSFNRS Senior Research Associate) are grateful to the "Fonds National de la Recherche Scientifique" (FRS-FNRS) for financial support and for the acquisition of SEC DMF (convention "Crédit aux Chercheurs" $\mathrm{n}^{\circ} 1.5 .006 .06$ ) and ${ }_{60}$ MALLS detector (convention F.R.F.C. $\mathrm{n}^{\circ} 2.4541 .07$ ). R.P. thanks the CNRS, the IUF and the Agence National de la Recherche (project OMRP, grant ANR 2010 BLANC 7101) for funding and the CINES and CICT (Project CALMIP) for granting free computational time.

65

${ }^{1}$ Center for Education and Research on Macromolecules (CERM),

University of Liège, Sart-Tilman, B6, 4000 Liège, Belgium

${ }^{2}$ Solvin s.a., rue de Ransbeek 310, 1120 Bruxelles, Belgium

${ }^{3}$ CNRS; LCC (Laboratoire de Chimie de Coordination); Université de

70 Toulouse; UPS, INPT; 205, route de Narbonne, F-31077 Toulouse,

France

${ }^{4}$ Institut Universitaire de France, 103, bd Saint-Michel, 75005 Paris,

France

$75 \dagger$ Electronic Supplementary Information (ESI) available: [details of any supplementary information available should be included here]. See DOI: $10.1039 / \mathrm{b} 000000 \mathrm{x} /$

\$ Footnotes should appear here. These might include comments relevant to but not central to the matter under discussion, limited 80 experimental and spectral data, and crystallographic data.

1. L. L. Semenycheva and D. F. Grishin, Russ. J. Appl. Chem., 2003, 76, $851-858$.

2. K. Endo, N. Kaneda and H. Waku, Polymer, 1999, 40, 6883-6886.

85 3. V. Percec, A. V. Popov, E. Ramirez-Castillo and O. Weichold, $J$. Polym. Sci., Part A: Polym. Chem., 2003, 41, 3283-3299.

4. J. Brandrup, Immergut, E.H., Grulke, E.A., .Eds, 1999, Polymer Handbook, 4th Edition, Wiley, New York.

5. D. Braun, J. Vinyl Addit. Technol., 2005, 11, 86-90.

90 6. G. David, C. Boyer, J. Tonnar, B. Ameduri, P. Lacroix-Desmazes and B. Boutevin, Chem. Rev., 2006, 106, 3936-3962.

7. T. Wannemacher, D. Braun, R. Pfaendner, Macromol. Symp. 2003, 202, 11-23.

8. R. Pfaendner, T. Wannemacher, D. Braun, PCT Int. Appl.: Ciba

95 Specialty Chemicals Hoding Inc., 2002, WO 02/38632. 
9. D. F. Grishin, L.L. Semenycheva, M.V. Pavlovskaya, K.V. Sokolov, Russ. J. Appl. Chem. 2001, 74, 1594-1599.

10. V. Sciannamea, R. Jerome and C. Detrembleur, Chem. Rev., 2008, 108, 1104-1126.

5 11. A. D. Asandei and V. Percec, J. Polym. Sci., Part A: Polym. Chem., 2001, 39, 3392-3418.

12. V. Percec, A. V. Popov, E. Ramirez-Castillo, M. Monteiro, B. Barboiu, O. Weichold, A. D. Asandei and C. M. Mitchell, J. Am. Chem. Soc., 2002, 124, 4940-4941.

10 13. V. Percec, A. V. Popov and E. Ramirez-Castillo, J. Polym. Sci., Part A: Polym. Chem., 2004, 43, 287-295.

14. V. Percec, A. V. Popov, E. Ramirez-Castillo and J. F. J. Coelho, J. Polym. Sci., Part A: Polym. Chem., 2005, 43, 773-778.

15. V. Percec, A. V. Popov, E. Ramirez-Castillo and O. Weichold, J.

15 Polym. Sci., Part A: Polym. Chem., 2004, 42, 6364-6374.

16. V. Percec, T. Guliashvili, A. V. Popov and E. Ramirez-Castillo, J. Polym. Sci., Part A: Polym. Chem., 2005, 43, 1478-1486.

17. V. Percec, T. Guliashvili, A. V. Popov, E. Ramirez-Castillo, J. F. J. Coelho and L. A. Hinojosa-Falcon, J. Polym. Sci., Part A: Polym. Chem., 2005, 43, 1649-1659.

18. J. F. J. Coelho, A. M. F. P. Silva, A. V. Popov, V. Percec, M. V. Abreu, P. M. O. F. Goncalves and M. H. Gil, J. Polym. Sci., Part A: Polym. Chem., 2006, 44, 3001-3008.

19. V. Percec, A. V. Popov, E. Ramirez-Castillo and L. A. HinojosaFalcon, J. Polym. Sci., Part A: Polym. Chem., 2005, 43, 22762280.

20. M. J. Sienkowska and V. Percec, J. Polym. Sci., Part A: Polym. Chem., 2009, 47, 635-652.

21. V. Percec and M. J. Sienkowska, J. Polym. Sci., Part A: Polym. 30 Chem., 2009, 47, 628-634

22. V. Percec, T. Guliashvili, J. S. Ladislaw, A. Wistrand, A. Stjerndahl, M. J. Sienkowska, M. J. Monteiro and S. Sahoo, J. Am. Chem. Soc., 2006, 128, 14156-14165.

23. M. J. Sienkowska, B. M. Rosen and V. Percec, J. Polym. Sci., Part A: Polym. Chem., 2009, 47, 4130-4140.

24. B. M. Rosen and V. Percec, Chem. Rev., 2009, 109, 5069-5119.

25. T. Hatano, B. M. Rosen and V. Percec, J. Polym. Sci., Part A: Polym. Chem., 2010, 48, 164-172.

26. C. M. R. Abreu, P. V. Mendonça, A. C. Serra, J. F. J. Coelho, A. V.

40 Popov, G. Gryn'ova, M. L. Coote and T. Guliashvili, Macromolecules 2012, 45, 2200-2208.

27. C. J. Hawker, A. W. Bosman and E. Harth, Chem. Rev., 2001, 101, 3661-3688.

28. W. A. Braunecker and K. Matyjaszewski, Prog. Polym. Sci., 2007,

$45 \quad 32,93-146$

29. M. Ouchi, T. Terashima, M. Sawamoto, Chem. Rev., 2009, 109, 4963-5050.

30. G. Moad, E. Rizzardo and S. H. Thang, Aust. J. Chem., 2009, 62, 1402-1472.

50 31. S. Yamago Chem. Rev., 2009, 109, 5051-5068.

32. B. B. Wayland, G. Poszmik, S. L. Mukerjee and M. Fryd, J. Am. Chem. Soc., 1994, 116, 7943-7944.

33. C.-H. Peng, J. Scricco, S. Li, M. Fryd and B. B. Wayland, Macromolecules, 2008, 41, 2368-2373.

55 34. S. Li, B. d. Bruin, C.-H. Peng, M. Fryd and B. B. Wayland, J. Am. Chem. Soc., 2008, 130, 13373-13381.

35. A. Debuigne, R. Poli, C. Jerome, R. Jerome and C. Detrembleur, Prog. Polym. Sci., 2009, 34, 211-239.

36. A. Debuigne, J.-R. Caille, C. Detrembleur and R. Jerome, Angew.

60 Chem., Int. Ed., 2005, 44, 3439-3442.

37. A. Debuigne, J.-R. Caille and R. Jerome, Angew. Chem., Int. Ed., 2005, 44, 1101-1104.

38. A. Debuigne, J.-R. Caille and R. Jerome, Macromolecules, 2005, 38, 5452-5458.

65 39. C. Detrembleur, A. Debuigne, R. Bryaskova, B. Charleux and R. Jerome, Macromol. Rapid Commun., 2006, 27, 37-41.

40. S. Maria, H. Kaneyoshi, K. Matyjaszewski and R. Poli, Chem. Eur. J., 2007, 13, 2480-2492.

41. R. Poli, Angew. Chem., Int. Ed., 2006, 45, 5058-5070.

70 42. K. M. Smith, W. S. McNeil and A. S. Abd-El-Aziz, Macromol. Chem. Phys., 2010, 211, 10-16.
43. M. Hurtgen, C. Detrembleur, C. Jérôme and A. Debuigne, Polym. Rev., 2011, 51, 188-213.

44. L. E. N. Allan, M. R. Perry and M. P. Shaver, Prog. Polym. Sci., 2012, 51, 188-213.

45. R. Poli, “Organometallic-Mediated Radical Polymerization.” In: K Matyjaszewski and M. Möller (eds.) Polymer Science: A Comprehensive , Amsterdam: Elsevier, 2012,, 3, 351-375.

46. H. Kaneyoshi and K. Matyjaszewski, Macromolecules, 2006, 39, 80 2757-2763.

47. A. Debuigne, N. Willet, R. Jerome, C. Detrembleur, Macromolecules, 2007, 40, 7111-7118.

48. A. Debuigne, R. Poli, J. De Winter, P. Laurent, P. Gerbaux, J.-P. Wathelet, C. Jerome and C. Detrembleur, Macromolecules 2010 ,

$85 \quad \mathbf{4 3}, 2801-2813$.

49. M. Hurtgen, J. Liu, A. Debuigne, C. Jérôme and C. Detrembleur J. Polym. Sci., Part A: Polym. Chem., 2012, 50, 400-408.

50. A. Debuigne, J. Warnant, R. Jerome, I. Voets, A. de Keizer, M. A.

Cohen Stuart and C. Detrembleur, Macromolecules, 2008, 41, 2353902360 .

51. A. Debuigne, C. Michaux, C. Jerome, R. Jerome, R. Poli and C. Detrembleur, Chem. Eur. J., 2008, 14, 7623-7637.

52. A. Debuigne, C. Jérôme and C. Detrembleur, Angew. Chem., Int. Ed., 2009, 48, 1422-1424.

95 53. M. Hurtgen, A. Debuigne, C. Jerome and C. Detrembleur, Macromolecules, 2010, 43, 886-894.

54. M. Hurtgen, A. Debuigne, C.-A. Fustin, C. Jerome and C. Detrembleur, Macromolecules, 2010, 44, 4623-4631.

55. A. Debuigne, Y. Champouret, R. Jerome, R. Poli and C. 100 Detrembleur, Chem. Eur. J., 2008, 14, 4046-4059.

56. K. S. Santhosh Kumar, Y. Gnanou, Y. Champouret, J.-C. Daran, R. Poli, Chem. Eur. J. 2009, 15, 4874-4885

57. A. Debuigne, R. Poli, R. Jerome, C. Jerome and C. Detrembleur, ACS Symp. Ser., 2009, 1024, 131-147.

105 58. G. Moad and D. H. Solomon, The Chemistry of Free Radical Polymerization., Pergamon, 1995.

59. H. A. Sarvetnick, Poly(vinyl chloride), 1969.

60. C. E. Wilkes, J. W. Summers, C. A. Daniels . Moad and D. H. Solomon, PVC Handbook, 2005.

110 61. T. P. Davis, D. Kukulj, D. M. Haddleton and D. R. Maloney, Trends in Polymer Science, 1995, 3, 365-373.

62. A. Gridnev, J. Polym. Sci., Part A: Polym. Chem., 2000, 38, 17531766.

63. A. A. Gridnev and S. D. Ittel, Chem. Rev., 2001, 101, 3611-3659.

115 64.G. Moad, D. H. Solomon, The Chemistry of Radical Polymerization, Second fully revised Edition; Elsevier, 2006.

65.A. D. Asandei, V. Percec, J. Polym. Sci., Part A: Polym. Chem. 2001, 39, 3392-3418.

66. W. H. Starnes, Jr., J. Polym. Sci., Part A: Polym. Chem., 2005, 43, 2451-2467.

67. G. M. Benedikt, R. J. Cozens, B. L. Goodall, L. F. Rhodes, M. N. Bell, A. C. Kemball and W. H. Starnes, Jr., Macromolecules, 1997, 30, 10-21.

68. M. F. Darricades-Llauro, A. Michel, A. Guyot, H. Waton, R.

125 Petiaud and Q. T. Pham, J. Macromol. Sci., Chem., 1986, A23, 221-269.

69. V. Percec, A. V. Popov, E. Ramirez-Castillo, J. F. J. Coelho and L. A. Hinojosa-Falcon, J. Polym. Sci., Part A: Polym. Chem., 2004, 42, 6267-6282.

130 70. V. Percec, E. Ramirez-Castillo, L. A. Hinojosa-Falcon and A. V. Popov, J. Polym. Sci., Part A: Polym. Chem., 2005, 43, 2185-2187.

71. J. Purmova, K. F. D. Pauwels, W. Van Zoelen, E. J. Vorenkamp, A. J. Schouten and M. L. Coote, Macromolecules, 2005, 38, 63526366.

135 72. C. J. M. Van den Heuvel and A. J. M. Weber, Makromolekulare Chemie, 1983, 184, 2261-2273.

73. J.-T. Xu, Q. Wang, F. Wu and Z.-Q. Fan, Eur. Polym. J., 2005, 41, $115-120$.

74. G. M. Benedikt, B. L. Goodall, L. F. Rhodes and A. C. Kemball,

140 Macromol. Symp., 1994, 86, 65-75.

75. T. Hjertberg and E. M. Sorvik, Polymer, 1983, 24, 673-684. 
76. V. Percec, A. V. Popov and E. Ramirez-Castillo, J. Polym. Sci., Part A: Polym. Chem., 2004, 43, 287-295.

77. H. Kaneyoshi and K. Matyjaszewski, Macromolecules, 2005, 38, 8163-8169.

5 78. R. Z. Greenley, J. Macromol. Sci., Chem., 1980, A14, 445-515.

79. G. C. Laurier, K. F. O'Driscoll and P. M. Reilly, J. Polym. Sci., Polym. Symp., 1985, 72, 17-26.

80. R. Z. Greenley, Polymer Handbook, 3rd Edition, 1989, II/153.

10 